\title{
圈/ QUEEN'S UNIVERSITY BELFAST

\section{Life cycle assessment of biodiesel production utilising waste date seed oil and a novel magnetic catalyst: A circular bioeconomy}

approach

S. Al-Mawali, K., Osman, A. I., Al-Muhtaseb, A. H., Mehta, N., Jamil, F., Mjalli, F., Vakili-Nezhaad, G. R., \& Rooney, D. W. (2021). Life cycle assessment of biodiesel production utilising waste date seed oil and a novel magnetic catalyst: A circular bioeconomy approach. Renewable Energy, 170, 832-846.

https://doi.org/10.1016/j.renene.2021.02.027

\section{Published in:}

Renewable Energy

\section{Document Version:}

Peer reviewed version

Queen's University Belfast - Research Portal:

Link to publication record in Queen's University Belfast Research Portal

\section{Publisher rights}

Copyright 2021 Elsevier.

This manuscript is distributed under a Creative Commons Attribution-NonCommercial-NoDerivs License

(https://creativecommons.org/licenses/by-nc-nd/4.0/), which permits distribution and reproduction for non-commercial purposes, provided the author and source are cited.

\section{General rights}

Copyright for the publications made accessible via the Queen's University Belfast Research Portal is retained by the author(s) and / or other copyright owners and it is a condition of accessing these publications that users recognise and abide by the legal requirements associated with these rights.

Take down policy

The Research Portal is Queen's institutional repository that provides access to Queen's research output. Every effort has been made to ensure that content in the Research Portal does not infringe any person's rights, or applicable UK laws. If you discover content in the

Research Portal that you believe breaches copyright or violates any law, please contact openaccess@qub.ac.uk. 
1 Life cycle assessment of biodiesel production utilising waste date seed oil and a novel magnetic catalyst: A circular bioeconomy approach

3

4

5

6

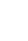

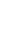

20

21

\section{Kamla S. Al-Mawali ${ }^{1}$, Ahmed I. Osman ${ }^{2 *}$, Ala'a H. Al-Muhtaseb ${ }^{1 *}$, Neha Mehta ${ }^{3}$, Farrukh} Jamil $^{1,4}$, Farouk Mjalli', G. Reza Vakili-Nezhaad", David W. Rooney²

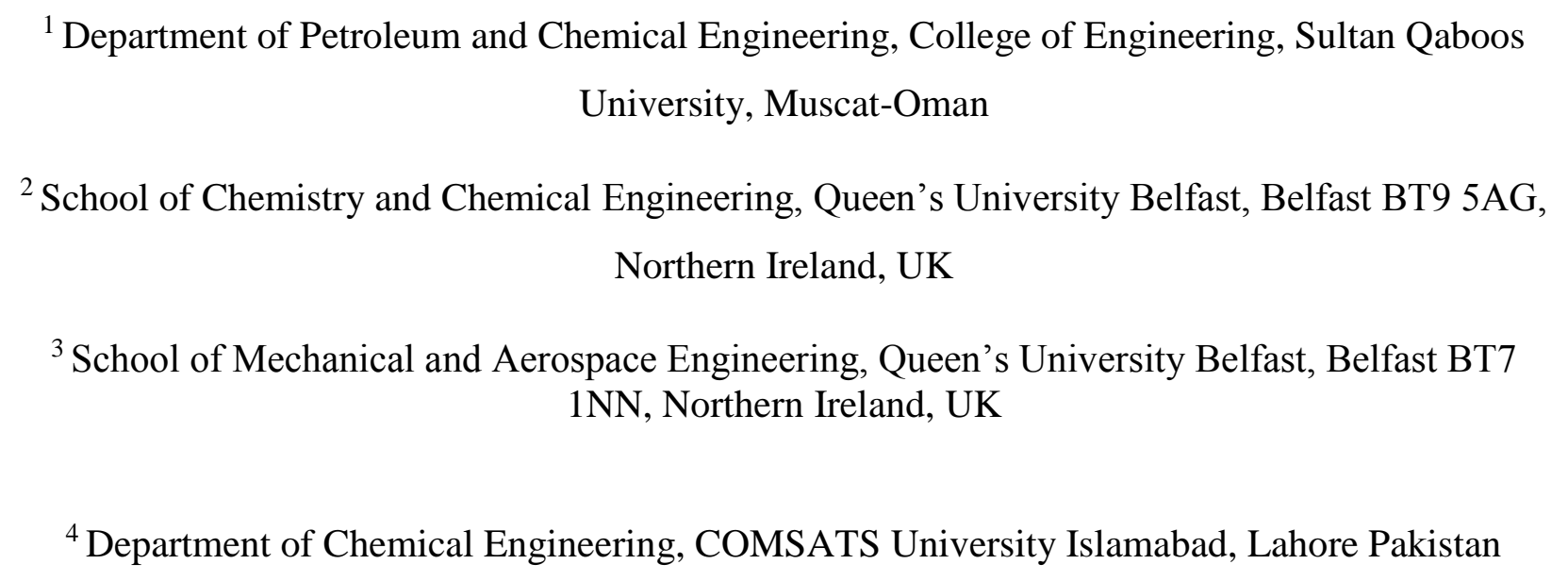

Corresponding Authors:

Dr. Ahmed I. Osman

Email: aosmanahmed01 @qub.ac.uk

Dr. Ala’a H. Al-Muhtaseb

Email:muhtaseb@squ.edu.om 


\section{Graphical abstract}

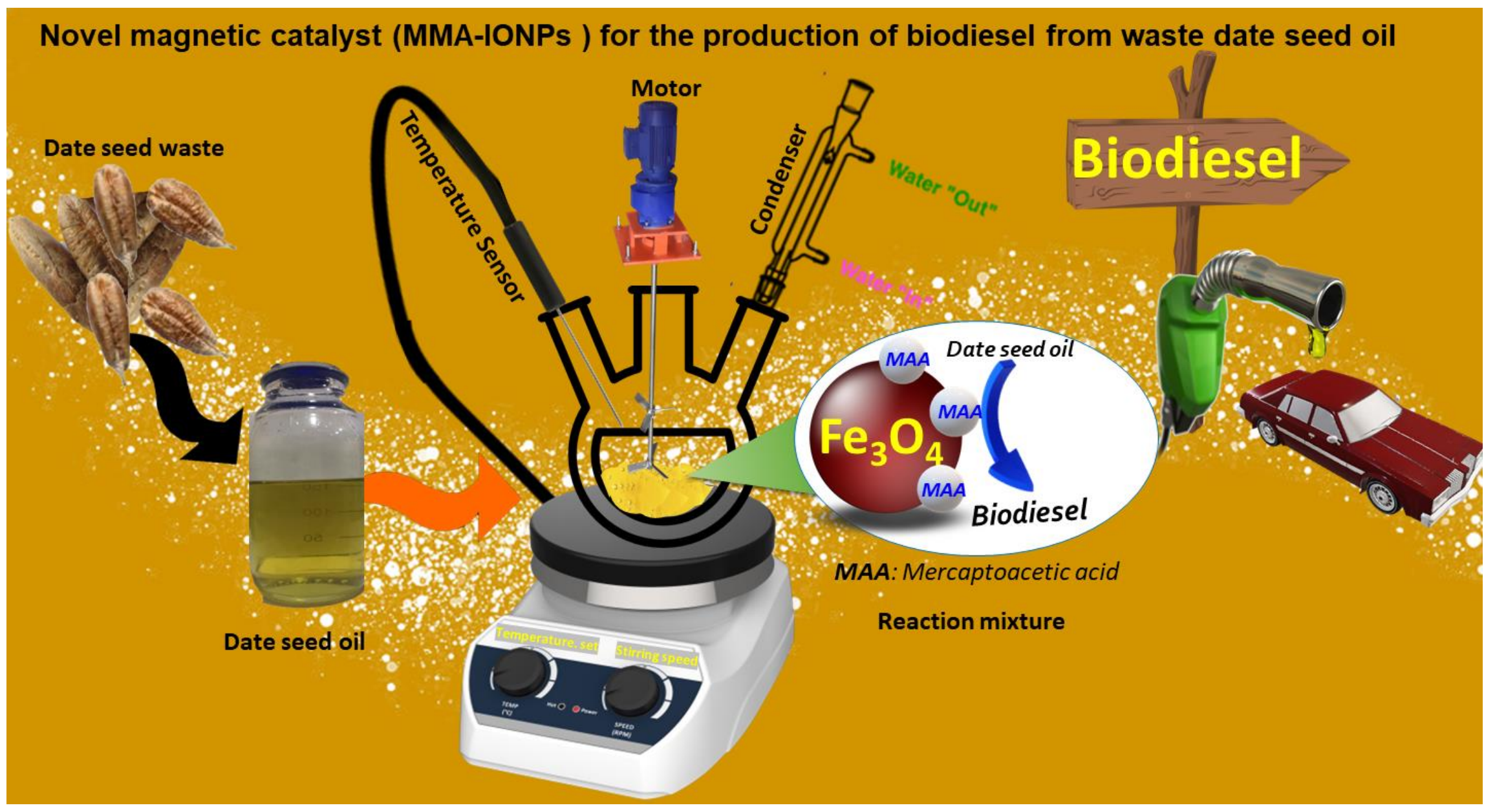


24 The utilisation of waste biomass in biodiesel production as a sustainable energy source can lead 25 to the incorporation of circular bioeconomy principles in the current economic systems. Herein, we synthesised a magnetically recyclable solid acid catalyst for the esterification of waste date

27 seed oil. The catalysts possessed superparamagnetic behaviour and high saturation magnetisation, allowing them to be easily separated from the reaction mixture using an external magnetic filed. The esterification reaction was modelled and optimised by RSM (Design Expert program) and parametric study. The magnetic solid acid catalyst showed high catalytic performance with $91.4 \%$ biodiesel yield with optimum conditions of residence time, catalyst

32 loading and temperature of $47 \mathrm{~min}, 1.5 \mathrm{wt} \%$, and $55^{\circ} \mathrm{C}$, respectively. The solid catalyst was easily recovered by simple magnetic decantation and reused five consecutive times without significant degradation in its catalytic activity. This approach of using waste date seed coupled with cheap magnetic solid acid catalyst has the potential to create more sustainable and cheap catalytic systems for biodiesel production. This will complete the full cycle of waste date seed

37 sustainably and facilitate the development of circular bioeconomy. The LCA results by using CML-IA baseline V3.06 midpoint indicators, for $1000 \mathrm{~kg}$ of biodiesel production showed the cumulative abiotic depletion of fossil resources over all the processes as 19037 MJ, global

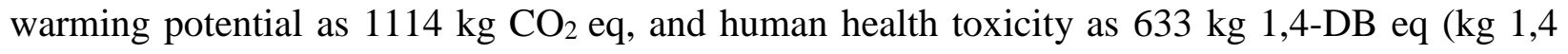

41 dichlorobenzene eq). The highest damage in all categories was observed during catalyst 42 preparation, and reuse, which was also confirmed in endpoint LCA findings performed using ReCiPe 2016 Endpoint (E) V1.04).

44 Keywords: Biodiesel, Magnetic catalyst, Date seed oil, Life cycle assessment, Parametric study, 45 Circular bioeconomy. 
47 The continuous increase in demand for energy sources pushes humankind to transition from 48 fossil-based linear ecosystems to circular bioeconomy approaches. In this context, circular 49 bioeconomy refers to the sustainable, resource-efficient valorisation of biomass in integrated, 50 multi-output production chains while also using residues and wastes and optimising the value of

51 biomass over time via cascading [1]. Upcycling waste biomass into sustainable fuel will help 52 facilitate economic development in a circular manner providing end uses or other uses in the 53 lifespan of waste lignocellulosic biomass feedstocks, minimising waste and promoting 54 sustainable development [2]. Biodiesel is considered as one of the most accepted alternative 55 transport fuels for diesel engines with comparable physical properties and is being used in diesel 56 engines without or with only minor modification [3]. Biodiesel is fatty acid methyl ester (FAME) 57 produced from vegetable oils such as jatropha oil, sunflower oil, cottonseed oil, soybean oil, 58 palm oil, peanut oil, rapeseed oil and corn oil or other sources like waste cooking oil, animal fats, 59 microalgae and greases $[4,5]$. Biodiesel can be produced through the transesterification reaction 60 of triglycerides or the esterification of free fatty acid content in the feed [6]. Contrast to fossil61 based diesel, biodiesel is characterised by its high biodegradability along with less toxicity with 62 lower sulfur content and higher flash point than that in diesel fuel $[7,8]$. It is worth noting that 63 there are mainly three ways to mitigate climate change and the utilisation of renewable energy is 64 one of the conventional ways $[9,10]$.

65 Using non-edible vegetable oil for biodiesel production is a promising solution as it does not 66 compete with food for human consumption [11]. Date seed is a waste part of many date 67 processing industries. Date seeds are a burden as solid waste except a little quantity is used for 68 animal feed such as poultry, camel, sheep and cattle [12]. Massive amounts of date seeds can be 
69 collected from date processing plants and industries by direct or indirect methods [13]. The

70 Phoenix Dactylifera (date palm) is the main tree grown in Middle Eastern countries, practically

71 in the Gulf cooperation council countries $[14,15]$. In certain countries, the date palm is a major

72 crop, that has covered more than $50 \%$ of the overall agriculture area. The main residue of the

73 date palm is the pits, which contain almost 10-15 wt.\% of the total residue and is also an inedible

74 part [12]. The amount of oil extracted from the date seed reached $16.5 \mathrm{wt} \%$, which is further

75 converted into biodiesel through esterification and transesterification processes [12, 14].

76 Biodiesel derived from waste date seed was recently investigated and shown to possess the fuel

77 properties that meet international standards [16].

78 Date seed oil cannot be easily converted to biodiesel due to the high content of free fatty acids

79 (FFAs). Thus, the conversion of date seed oil requires more complicated processing. When a

80 basic homogenous catalyst is used for the transesterification of oil feed with FFAs, soaps are

81 formed as a by-product through undesirable saponification reaction leading to a decrease in the

82 produced biodiesel yield [8]. That said, an acidic catalyst can be used to circumvent this issue. A

83 homogenous acidic catalyst such as $\mathrm{H}_{2} \mathrm{SO}_{4}$ can be used with an accurate reduction of acidity

84 [17]. However, this conventional catalyst causes serious contamination problems. The pretreated

85 oil must be completely cleaned from catalytic residual, which are highly corrosive and risky

86 when combusted with fuel [18]. Therefore, several studies have been performed on solid

87 catalysts to convert FFAs into esters by the esterification reaction. Thus, this leads to the

88 formation of methyl ester under acidic condition when methanol is the common alcohol being

89 used herein [19]. Moreover, in the common industrial process, heterogeneous catalysts are a

90 more attractive method for any chemical reactions because they are recyclable, non-corrosive

91 and separable. The use of solid catalysts would also decrease the number of reaction and 
92 separation stages required in the transformation of fats and oil to biodiesel, providing for more

93 economical processing and producing high-quality ester product and glycerol [20, 21].

94 Magnetic nanoparticles (MNP) with good properties have found substantial nanomedicine 95 applications, magnetic sealing, separation technology, electronics and catalysis [22, 23]. Among 96 them, magnetite $\left(\mathrm{Fe}_{3} \mathrm{O}_{4}\right)$ nanoparticles as transition metal oxides are most active and widely 97 applicable. They are easy to synthesise at low cost and are much less toxic than other magnetic nanoparticles [24]. In common applications, magnetite nanoparticles have to be coated with a 99 stabiliser to improve chemical stability, colloidal, and add further functionalisation [25]. The 100 coating is performed using various organic (stabiliser), inorganic and metal materials. Different 101 studies discovered that coating with stabilisers could impact the shape, size, and magnetism of 102 the MNP and other factors such as temperature, concentration, type of anions, ionic strength, and $103 \mathrm{pH}$ or exposure to an external magnetic field [26]. Mercaptoacetic acid is an example of the 104 stabiliser which can be used for coating iron oxide and potentially changing the acidity of the 105 nanoparticles.

106 Furthermore, it works as a catalyst for the esterification reaction to reduce the acid value of oil. 107 The optimum set of operational conditions obtained has been reported [14]: temperature of 70 $108{ }^{\circ} \mathrm{C}$, solvent to seed ratio of $4: 1$ and a time of $7 \mathrm{~h}$, so, the yield of oil extracted at optimum 109 conditions was 16.5 wt.\%. Kazemi et al. [27] reported on oil extraction from various date seeds, 110 with the maximum reported was from the Khazravi variety (13.2 wt.\%).

111 Therefore, the present study aimed to produce biodiesel using waste date seed oil and iron oxide 112 nanoparticles coated with the mercaptoacetic acid catalyst. Specifically, the objectives of this 113 study were to: (1) synthesise iron oxide nanoparticles coated with the mercaptoacetic acid 114 catalyst from the solvothermal method, which was further used for the esterification reaction of 
115 waste date seed oil with methanol; (2) investigate the performance of the catalyst through the 116 parametric study of the practical and mathematical approaches. The effect of various reaction

117 parameters such as catalyst loading, temperature and residence time were studied. Those factors

118 of the reaction conditions were modelled and optimised for the highest catalytic conversion 119 along with better catalyst stability for biodiesel production, and (3) conduct life cycle assessment 120 (LCA) for analysing the environmental feasibility of the biodiesel production process. LCA is a 121 systematic tool that evaluates the environmental impacts of a product through the entire 122 production process, including the primary production process and final disposal after use (ISO: 123 14044) [28].

\section{Materials and methodology}

125 Date seed (Phoenix Dactylifera L.) samples were collected from local farmlands. Prior to oil 126 extraction date seeds washed thoroughly and oven-dried. The date seed waste along with its 127 powder form and grinder are shown in Figure S1. Dried date seeds powder is subjected to oil 128 extraction, and extraction was done using AOCS Official Method Am 2-93. Methanol and n129 Hexane were purchased from Fisher scientific company (UK). Potassium hydroxide, Ferric 130 chloride hexahydrate and ethanol were purchased from Merck Company (Germany). Ethylene 131 glycol and mercaptoacetic acid were purchased from Alfa Aesar company (Germany). All other 132 chemicals were commercially available and used without further purification.

\subsection{Characterisation of date seed oil}

134 Oil extracted from date seeds is characterised by several techniques to determine its suitability 135 for fuel production. Fatty acid content was determined using GC-MS analysis, and it was done 136 using Shimadzu GC-2010 Plus, fitted with an SP-2560 Supelco capillary column $(100 \mathrm{~m} \times 0.250$ 
$137 \mathrm{~mm}$ I.D. $\times 0.2 \mu \mathrm{m}$ film thickness) coupled to GCMS-QP2010 ULTRA MS. Ultra-high purity

138 helium (99.99\%) was used as a carrier gas at a constant flow of $1.0 \mathrm{ml} / \mathrm{min}$. The injection,

139 transfer line and ion source temperatures were 250,240 and $230{ }^{\circ} \mathrm{C}$, respectively. The ionising

140 energy was $70 \mathrm{eV}$. Electron multiplier (EM) voltage was obtained from auto-tune. All data were

141 obtained by collecting the full-scan mass spectra within the scan range 35-500 amu. The injected

142 sample volume was $1 \mu \mathrm{l}$, with a split ratio of 50:1. The oven temperature program was $50{ }^{\circ} \mathrm{C}$

143 (held for 5 minutes) and a heating rate of $4{ }^{\circ} \mathrm{C} \cdot \min ^{-1}$ up to $250{ }^{\circ} \mathrm{C}$, then held for 5 minutes. The

144 oil compounds were identified by comparing the spectra obtained with mass spectrum libraries

145 (NIST 2011 v.2.3 and Wiley, $9^{\text {th }}$ edition) and further confirmed with Supelco 37 component

146 FAME mixture. FTIR was utilised to identify the functional groups present in the oil sample.

147 Iodine value or iodine number is referred to as a degree of unsaturation of oil sample. The Iodine

148 value was performed as described in the ESI and calculated as in equation 1.

149 Iodine Value $=\frac{A \times B \times C \times 100 \times 10^{-3}}{D}$

150 where, $\mathrm{A}=$ equivalent weight of iodine is $127, \mathrm{~B}=$ volume of sodium thiosulfate $=\mathrm{V}_{1}-\mathrm{V}_{2}, \mathrm{~V}_{1}=$ 151 volume $(\mathrm{mL})$ of sodium thiosulfate for a blank test, $\mathrm{V}_{2}=$ volume $(\mathrm{mL})$ of sodium thiosulfate for 152 oil sample, $\mathrm{C}=$ normality of sodium thiosulfate and $\mathrm{D}=\mathrm{wt}$. of oil sample for analysis. The 153 saponification is calculated using Equation 2, then was used for calculating acid value:

154 Saponification Value $(m g K O H / g$ of oil $)=\frac{(B-S) \times N \times M . W}{W}$

155 where $\mathrm{B}$ is the volume of $\mathrm{HCl}$ solution used in the blank run, $\mathrm{S}$ is the volume of $\mathrm{HCl}$ solution 156 used in the original run, $\mathrm{N}$ is the normality of $\mathrm{KOH}, \mathrm{M} . \mathrm{W} .=$ molecular weight of $\mathrm{KOH}$ and $\mathrm{W}=$ 157 weight of oil sample. The acid value was calculated according to the following equation 3: 
158 Acid Value $(m g \mathrm{KOH} / \mathrm{g}$ of oil $)=\frac{A \times N \times 56.1}{W}$

159 Where 56.1 is the molecular weight of $\mathrm{KOH}(\mathrm{g} / \mathrm{mol}), \mathrm{N}$ is the normality of $\mathrm{KOH}(\mathrm{mEq} / \mathrm{mL}), \mathrm{A}$ is 160 the volume of the $\mathrm{KOH}(\mathrm{mL})$ used for titration and $\mathrm{W}=$ weight of oil sample $(\mathrm{g})$. The kinematic 161 viscosity of oil samples was measured according to the standard method defined as American 162 Society for Testing and Materials (ASTM) D445-446 by using a Ubbelohde viscometer based on 163 the capillary action.

\subsection{Catalyst preparation and characterisation}

165 Magnetic $\mathrm{Fe}_{3} \mathrm{O}_{4}$ nanoparticles were synthesised by a solvothermal method, where $2.7 \mathrm{~g}$ of $166 \mathrm{FeCl}_{3} \cdot 6 \mathrm{H}_{2} \mathrm{O}$ and $5.75 \mathrm{~g}$ of sodium acetate were dissolved in $50 \mathrm{~mL}$ of ethylene glycol and stirred 167 for $1 \mathrm{~h}$. The homogeneous yellow mixture solution was then transferred to a Teflon-lined 168 stainless-steel autoclave and heated at $200{ }^{\circ} \mathrm{C}$ for $8 \mathrm{~h}$. After cooling down to ambient conditions, 169 the black microspheres were separated with an external magnet, washed with ethanol several 170 times, and finally dried in a vacuum oven at $60{ }^{\circ} \mathrm{C}$ for $12 \mathrm{~h}$. The surface modification of 171 nanoparticles by mercaptoacetic acid was performed using $1 \mathrm{~g}$ of $\mathrm{Fe}_{3} \mathrm{O}_{4}$ distributed in $80 \mathrm{~mL}$ of 172 an ethanolic Mercaptoacetic acid solution (1.74 mmol/L) and constantly stirred for $24 \mathrm{hr}$. The 173 carboxyl-modified $\mathrm{Fe}_{3} \mathrm{O}_{4}$ (Called as MAA-IONPs) was separated by an external magnetic field 174 and washed with ethanol and water several times. Then the produced catalyst was dried in a 175 vacuum oven at $60^{\circ} \mathrm{C}$ for overnight. The catalysts were characterised with different techniques 176 such as Powder X-ray diffraction (XRD), Brunauer-Emmett-Teller (BET) surface area, 177 Scanning electron microscopy (SEM), the thermal gravimetric analysis (TGA), vibrating sample 178 magnetometer (VSM) and Fourier transform infrared spectroscopy (FTIR) with their full 179 description is provided in the ESI. 


\subsection{Esterification reaction and experimental design}

181 Esterification of waste date seed oil using the MMA-IONPs catalyst was carried out in a batch

182 run on a hot plate with a magnetic stirrer at different process conditions. When the reaction was

183 completed, the catalyst was separated by an external magnet and then by filtration to ensure that

184 all the catalyst particles were removed from the biodiesel sample. The biodiesel yield was

185 calculated by using equation 4. Then the acid value was measured and calculated by following

186 the procedure mentioned earlier.

187 Yield $(\%)=\frac{\text { weight of biodiesel }}{\text { weight of oil }} \times 100$

188 To investigate the effect of various process parameters on the biodiesel yield, experiments 189 undertaken were selected using Box Behnken Design (CCD) a mode in RSM (Response Surface 190 Methodology), using Design-Expert 9.0 (Stat-Ease, Inc) software. The independent variables 191 selected for consideration were temperature, time and catalyst loading, while the percentage of 192 FFAs conversion (biodiesel yield) was the response variable. Table 1 shows the esterification 193 process conditions and the percentage of FFAs conversions (biodiesel yield) obtained; a total of 19414 experiments were required following BBD methodology, including experiments covering all 195 range of independence variables, of which 12 were factorial point and 2 were on the centre point. 196 The range of the independent variables was coded into low (-1) and high (+1) levels, where 197 experiments were repeated twice for reproducibility. Moreover, the experiment was carried out 198 in random order to avoiding any systemic error. 
Table 1: Experimental plan with varying three process parameters for esterification reaction.

\begin{tabular}{|c|c|c|c|c|}
\hline Run & Time $(\mathrm{hr})$ & $\mathrm{T}\left({ }^{\circ} \mathrm{C}\right)$ & $\mathrm{S}(\mathrm{wt} \%)$ & Biodiesel Yield $(\%)$ \\
\hline $\mathbf{1}$ & 0.5 & 55 & 2.5 & 87.5 \\
\hline $\mathbf{2}$ & 1.25 & 55 & 3.5 & 82.4 \\
\hline $\mathbf{3}$ & 2 & 55 & 2.5 & 85.0 \\
\hline $\mathbf{4}$ & 1.25 & 60 & 2.5 & 74.7 \\
\hline $\mathbf{5}$ & 2 & 60 & 1.5 & 52.6 \\
\hline $\mathbf{6}$ & 2 & 65 & 2.5 & 46.1 \\
\hline $\mathbf{7}$ & 0.5 & 60 & 1.5 & 87.9 \\
\hline $\mathbf{8}$ & 1.25 & 55 & 1.5 & 91.4 \\
\hline $\mathbf{9}$ & 1.25 & 65 & 3.5 & 85.7 \\
\hline $\mathbf{1 0}$ & 1.25 & 60 & 2.5 & 80.6 \\
\hline $\mathbf{1 1}$ & 2 & 60 & 3.5 & 85.4 \\
\hline $\mathbf{1 2}$ & 0.5 & 65 & 2.5 & 83.3 \\
\hline $\mathbf{1 3}$ & 1.25 & 65 & 1.5 & 80.7 \\
\hline $\mathbf{1 4}$ & 0.5 & 60 & 3.5 & 81.1 \\
\hline
\end{tabular}

\subsection{Statistical Analysis}

203 The statistical analysis of the experimental data obtained was performed using a response surface 204 methodology (RSM). The significance of the model was evaluated by the analysis of variance 205 (ANOVA) in which a p-value (probability value) of less than 0.05 was considered significant 206 with 95\% confidence, and the coefficient of determination, $\mathrm{R}^{2}$, and lack of fit was assessed to 207 ensure that the predicted model was the most suitable for the experiments undertaken. A 208 parametric study was carried out based on 3D and contour plots obtained using the predicted 209 model, which shows the interactive effect of independent variables on the response factor. The 210 interaction between the response variable and the independent variables was correlated by a 211 model described in equation 5.

$212 y=\beta_{o}+\sum_{i=1}^{k} \beta_{i i} x_{i i}+\sum_{i=1}^{k} \beta_{i=1} x_{i}^{2}+\sum i=1 \sum j=i+1 \beta_{i i} x_{i i}+\varepsilon$ 
213 Where: $y$ represents the biodiesel, while $\beta_{\mathrm{o}}, \beta_{\mathrm{ii}}$ and $\beta_{\mathrm{ij}}$ are the model coefficients and $\mathrm{x}_{\mathrm{i}}$ and $\mathrm{x}_{\mathrm{ij}}$ are 214 coded factors (independent variables).

\section{Results and discussion}

The oil extracted from date seed was yellow in colour (Figure S2) with a distinct odour. Moreover, it was clear that there were no suspended particles observed. Even after storage for several days of extraction, odour and appearance remained the same, and there was no solid formation. This implies that the oil is highly stable and can be used for different applications without heating and can be extracted and stored for further utilisation in biodiesel production. potassium hydroxide required to neutralise the free fatty acids present in one gram of oil. As the acid value decreases, the amount of carboxylic acids presents in the oil decreases. The measurement of acid value is crucial before further processing for biodiesel production. Based on

227 this value, all considerations are considered, such as type of catalysts either acidic or basic and whether the oil be directly subjected to transesterification or it should be treated with acidic 229 catalysts to reduce acid value and amount of alcohol. Moreover, it provides information on 230 whether the oil is stable or not, hence measuring its suitability for long storage periods. It is well 231 known that long storage periods can lead to the decomposition of organic matter by oxidation of 232 fatty acids. In the present study, the acid value for date pits was observed to be $20 \mathrm{mg} \mathrm{KOH} / \mathrm{g}$.

233 The date pit oil density was measured using an Anton Paar instrument (DMA 4500M, USA) in 234 accordance with ASTM D-4052 standard method. Density is defined as the amount of oil per 
235 volume. It is an intrinsic property, so it does not depend on the amount of sample but depends on

236 the measuring parameter such as temperature. The density measured of date pits oil was 0.92

237 g.cm ${ }^{-3}$ at atmospheric conditions. The viscosity was determined following the method specified

238 by ASTM D445. Normally, plant-based oils are highly viscous, thus not appropriate as a direct

239 fuel. So, by alcoholysis for biodiesel production, viscosity is reduced, and this should satisfy

240 international standards. The viscosity of date pits oil was measured to be $23.56 \mathrm{~mm}^{2} . \mathrm{s}^{-1}$ which is

241 lower than that of most of the traditional oils currently used for biodiesel synthesis, such as

242 soybean oil $27.45 \mathrm{~mm}^{2} \cdot \mathrm{s}^{-1}$ [29], Yucca aloifolia oil $25.86 \mathrm{~mm}^{2} \cdot \mathrm{s}^{-1}$ [29] and sunflower oil 29.53

$243 \mathrm{~mm}^{2} \cdot \mathrm{s}^{-1}[30]$.

244 The fatty acid (FA) composition of date pits oil presented in Table 2, shows that date pits oil 245 contains $52.22 \%$ unsaturated fatty acids (UFA) and $47.78 \%$ of saturated fatty acid (SFA). Table

2462 shows the FFA profile for some common biodiesel fuel feedstocks, including palm oil, Yucca

247 aloifolia oil and sunflower oil. Table 2 results show that although the amounts of individual fatty

248 acids vary, almost the same acids constitute the fatty acid profiles. The fatty acids derived from

249 different oils used for biodiesel synthesis possess similar fractions and are similar to those

250 currently used in biodiesel production. Thus, by comparing the FA composition of the date pits

251 oil herein along with other feedstocks used for biodiesel synthesis, it can be concluded that date

252 pit oil can be considered a potential feedstock for biodiesel production. 
Table 2: Fatty acid profile of date pits oil along with fatty acid profiles of other plant-based oils used for biodiesel reported in the literature for comparison to prove the feasibility of date pits oil 256 for biodiesel production.

\begin{tabular}{|c|c|c|c|c|}
\hline & $\begin{array}{c}\text { Date Seed } \\
\text { Oil }\end{array}$ & Palm Oil [31] & $\begin{array}{l}\text { Yucca aloifolia } \\
\text { oil [29] }\end{array}$ & Sunflower Oil [30] \\
\hline Lauric (C 12:0) & 16.36 & 0.26 & - & - \\
\hline Myristic (C 14:0) & 13.25 & 2.43 & - & - \\
\hline Palmitic (C 16:0) & 15.79 & 46.13 & 8.59 & 7 \\
\hline Stearic (C 18:0) & 2.38 & 3.68 & 2.15 & 3.5 \\
\hline Oleic (C 18:1) & 45.9 & 37.47 & 13.93 & 33.35 \\
\hline Linoleic (C 18:2) & 6.32 & 11.03 & 70.77 & 55.25 \\
\hline Linolenic (C 18:3) & - & - & 2.5 & - \\
\hline
\end{tabular}

258 The saponification value for the oil extracted from date pits was $236 \mathrm{mg} \mathrm{KOH} / \mathrm{g}$ of oil. It has 259 been observed that long-chain fatty acids in fats show a small saponification value as they 260 contain a lower number of carboxylic functional groups as compared with short-chain fatty acids. 261 Thus, the fact that a high value of milligrams of $\mathrm{KOH}$ is required for saponification implies the 262 presence of a high quantity of short-chain fatty acid.

263 The iodine value of oil tends to indicate the degree of unsaturation of oil, which refers to the 264 presence of $\mathrm{C}=\mathrm{C}$ in the fatty acids. It is one of the major properties to be determined for oil to be 265 transformed into biodiesel as it can also help predict the low-temperature behaviour of oil. The 266 iodine value for date pits oil was determined and found to be $49 \mathrm{~g}$ of $\mathrm{I}_{2} / 100 \mathrm{~g}$. The date pits oil 
267 contains a higher amount of unsaturated fatty acids, so this can be determined from the iodine 268 value. Rashid et al. [32] reported that Muskmelon oil extracted for biodiesel production has an 269 iodine value of $87.49 \mathrm{~g}$ of $\mathrm{I}_{2} / 100 \mathrm{~g}$; thus muskmelon oil has a higher amount of unsaturated fatty 270 acids compared to date pits oil. It has been reported that Moringa Oleifera oil, as a non-edible 271 feedstock and has been used for biodiesel production, showed an iodine value of $70.50 \mathrm{~g}$ of $272 \mathrm{I}_{2} / 100 \mathrm{~g}$ [33]. Thus, Moringa Oleifera oil also has more unsaturated fatty acids than date pits oil.

273 Figure 1a shows the FTIR spectrum of the date seed oil that has been extracted by n-hexane 274 solvent. The absorption band at $584 \mathrm{~cm}^{-1}$ represent various inorganic compounds. The absorption 275 band at $721 \mathrm{~cm}^{-1}$ is characterised to the aromatic compounds [34], while the absorption bands at $276852-1114 \mathrm{~cm}^{-1}$ region are represented to the stretching vibration of $\mathrm{C}-\mathrm{O}$ ester and the $\mathrm{CH}_{2}$ 277 groups. The absorption band at $1160 \mathrm{~cm}^{-1}$ is attributed to the $\mathrm{C}-\mathrm{O}$ stretching alcohols groups. 278 The absorption bands in the region of $1200-1400 \mathrm{~cm}^{-1}$ are mostly assigned to the bending 279 vibrations of $\mathrm{CH}_{2}$ and $\mathrm{CH}_{3}$ aliphatic groups like symmetric $\mathrm{HCH}$ bending at $1376 \mathrm{~cm}^{-1}$ and $\mathrm{CH}_{2}$ 280 scissoring at $1457 \mathrm{~cm}^{-1}$. The absorption band at $1744 \mathrm{~cm}^{-1}$ is assigned to the $\mathrm{C}=\mathrm{O}$ stretching 281 vibration of carboxylic acids of the ester. The two small absorption bands at $1652 \mathrm{~cm}^{-1}$ and 3648 $282 \mathrm{~cm}^{-1}$ correspond to the bending and stretching vibration of $\mathrm{O}-\mathrm{H}$ bonds of the $\mathrm{H}_{2} \mathrm{O}$ molecule in the 283 oil [35]. 

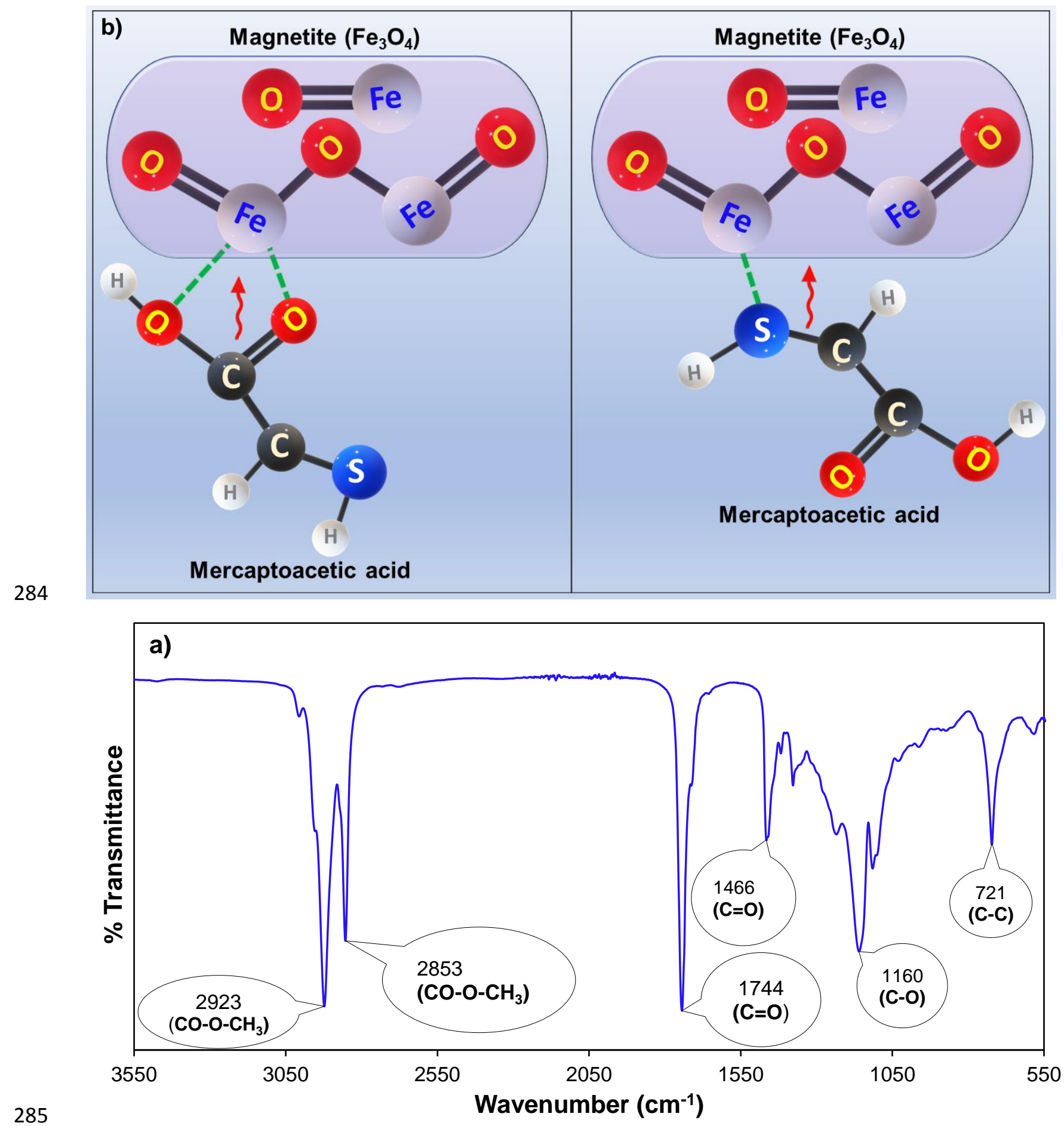

287 Figure 1: shows a) The FTIR spectrum of date seed oil along with b) the schematic 288 representation of the possible attachments of mercaptoacetic acid on iron oxide metal support. 
291 Herein a magnetic solid acid catalyst was synthesised with the advantages of easy separation and

292 reusability compared to homogenous catalysts. It consists of mercaptoacetic acid supported on 293 iron oxide nanoparticles $\left(\mathrm{Fe}_{3} \mathrm{O}_{4}\right)$ as an acidic catalyst. The schematic representation for the 294 attachment of mercaptoacetic acid on iron oxide nanoparticles (IONPs) is shown in Figure 1b, 295 where the iron metal is bonded to either the carboxylic group (-COOH) or the mercaptans group 296 (S-H). The XRD analysis of IONPs and the modified mercaptoacetic acid-iron oxide 297 nanoparticles by (MMA-IONPs) are shown in Figure 2a. The diffraction lines of IONPs are 298 attributed to the XRD for iron oxide nanoparticles at $2 \theta$ of $18.2,30.1,35.4,43,53.4,56.9$ and $29962.6^{\circ}$ (JCPDS card no. 39-1346), so the preparation of nanoparticles was achieved with a 300 calculated particle size of $27.7 \mathrm{~nm}$ [36]. The comparison between the synthesised catalyst herein 301 and the literature is shown in Table S1, where other catalyst prepared with the same solvothermal 302 method showed particle sizes of 45-80 nm [37]. The MMA-IONPs also have the same diffraction 303 lines as IONPs; thus, iron oxide nanoparticles' coating material did not affect the crystalline of 304 the IONPs.The surface morphology and elemental composition of synthesised catalysts were 305 analysed by SEM and EDS, as shown in Figure 2b. The IONPs catalyst's micrographs showed 306 spherical particles; also, the introduction of MMA-IONPs displayed a similar shape with a 307 difference in the distribution of nanoparticles on the surface. The corresponding EDS result 308 showed that the wt.\% of $\mathrm{C}$ element for nanoparticles uncoated and nanoparticles coated 309 presented 13.6 and $26.2 \mathrm{wt} \%$, respectively. While for the iron element, the values were 59.7 and $31043.6 \mathrm{wt} . \%$, respectively. These results confirm the nanoparticles' coating by the organic material, 311 because the percentages of carbon, present in MMA-IONPs, increased approximately by 12.6 312 wt.\% after coating. 


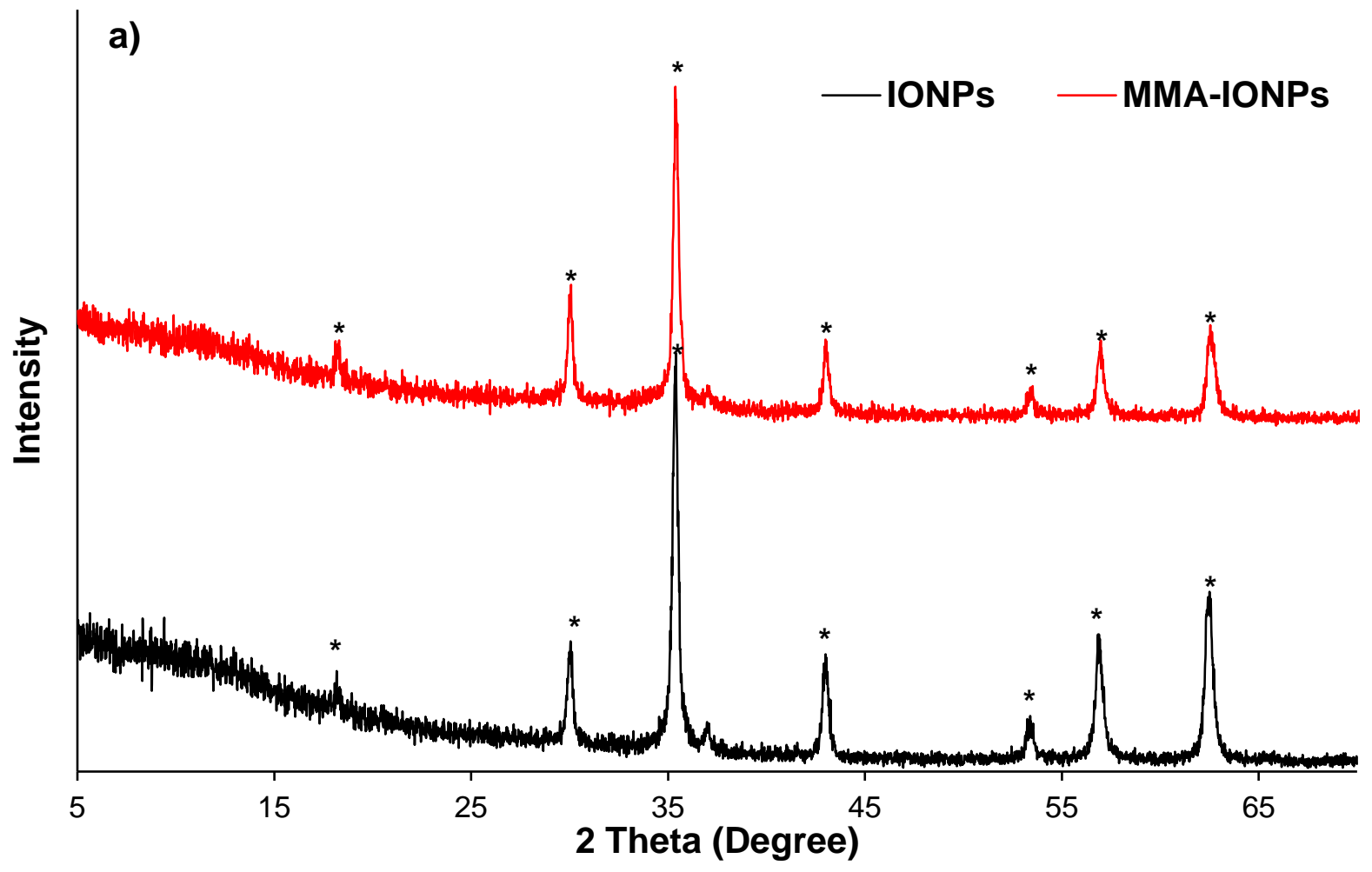

b)
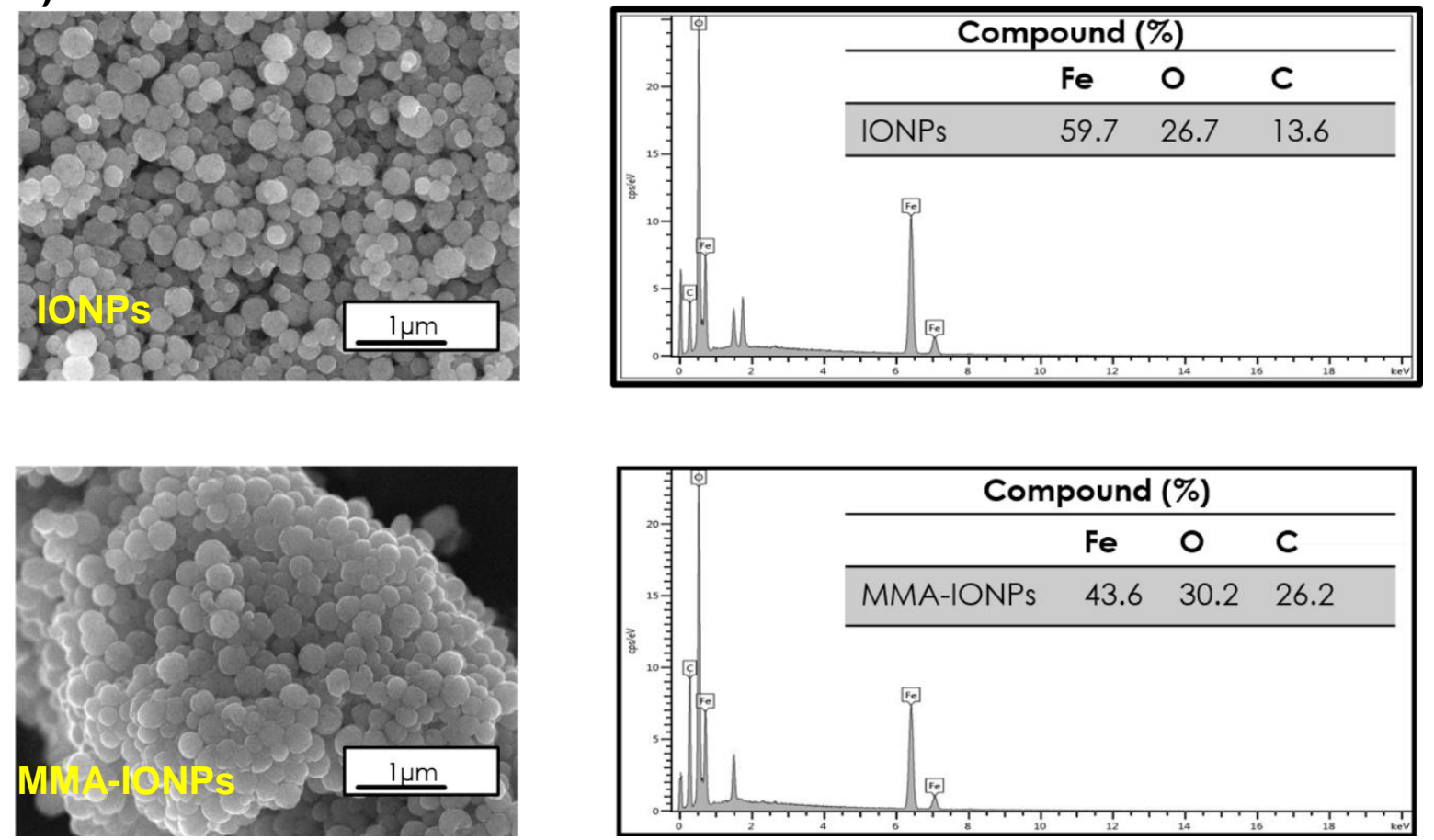

Figure 2: shows a) X-ray diffraction of IONPs and MMA-IONPs along with b) SEM/ EDS of

316 IONPs and MMA-IONPs catalysts. 
317 The behaviour of the iron nanoparticles in water or toluene can be observed in Figure 3. The pure

318 magnetic nanoparticles remain suspended in the aqueous medium due to the oxide material's

319 hydrophilic surface, as shown in Figure 3a. Figure $3 b$ demonstrates the suspension of iron

320 nanoparticles coated by mercaptoacetic acid in between water and toluene. Obviously, coating

321 with organic material makes them hydrophobic and apart from water into between the two-

322 phases. This behaviour revealed that the novel catalyst was an amphiphilic compound which can

323 dissolve in two phases.

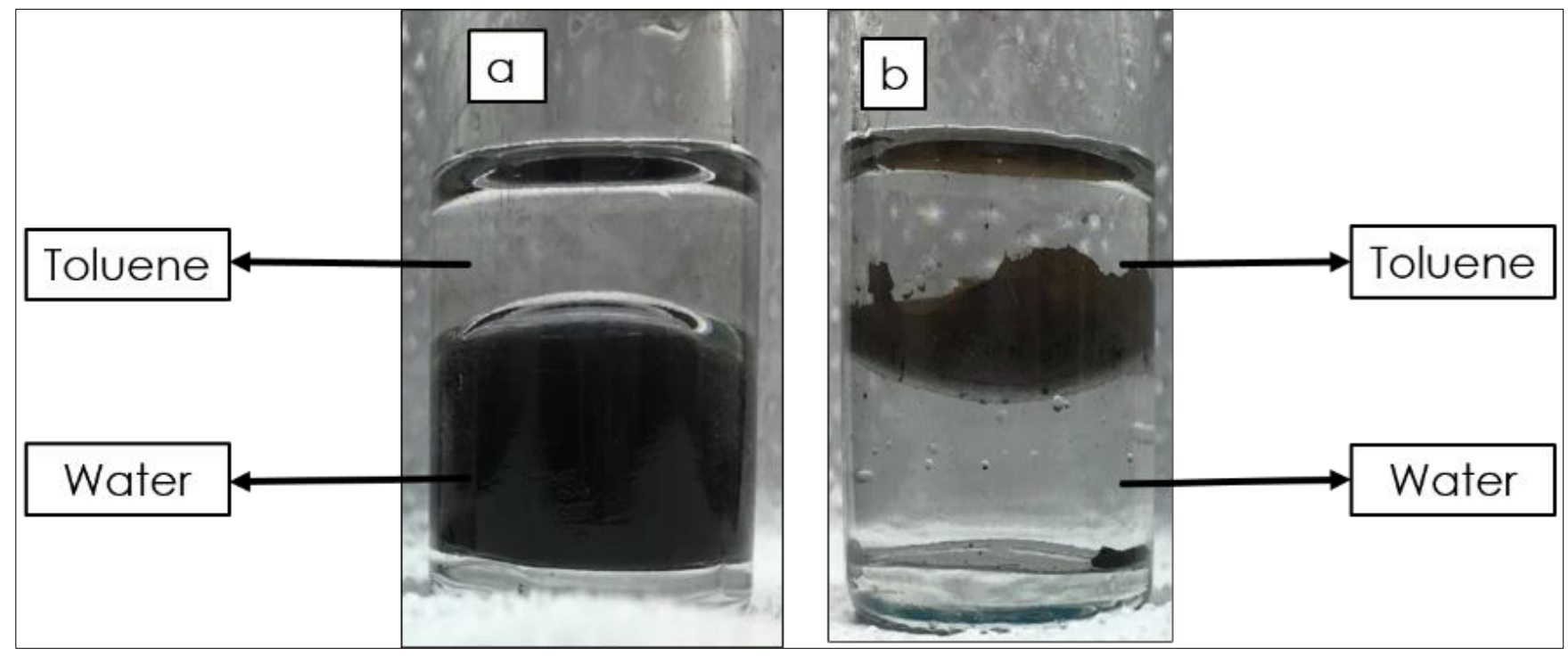

325 Figure 3: the behaviour of pure iron nanoparticles (IONPs) and coating nanoparticles (MMA-

326 IONPs) in the water-toluene system.

328 The FTIR spectra of Figure S3 compares the pure iron oxide nanoparticles (IONPs) and the modified mercaptoacetic acid- iron oxide nanoparticles (MMA-IONPs). The nanoparticles of 330 iron oxide (IONPs) showed absorption bands in the region of 571 and $620 \mathrm{~cm}^{-1}$, attributed to the 331 Fe-O group. The band at $1724 \mathrm{~cm}^{-1}$ is related to the carbonyl group's stretching of the carboxylic 332 anhydride and generates an overlapping of $\mathrm{C}=\mathrm{O}$ band [38]. The bands at 1630 and $3400 \mathrm{~cm}^{-1}$ are 
333 assigned to the $\mathrm{OH}$ group's vibration coated on the surface of iron oxide [39]. The symmetric and 334 asymmetric stretching of $\mathrm{CH}$ groups in the MMA-IONPs are observed at 2856 and $2925 \mathrm{~cm}^{-1}$, 335 respectively [40]. Thermogravimetric analysis was done to investigate the modified catalyst's 336 thermal degradation by mercaptoacetic acid- iron oxide nanoparticles (Figure 4a). The 337 thermogravimetric curve of pure nanoparticles showed weight loss of approximately 1 wt.\%, 338 where the first mass loss step occurred at relatively $100{ }^{\circ} \mathrm{C}$, which is related to the water 339 adsorbed on the surface of the magnetite nanoparticles. Unlike the pure magnetite nanoparticles, 340 the MMA-IONPs showed three weight loss stages with a higher weight loss of 2.25 wt.\% 341 compared to the pure magnetite nanoparticles catalyst. The first, second and third weight losses 342 were observed at temperature ranges of $130-140,280-300$ and $380-390{ }^{\circ} \mathrm{C}$, respectively. Those 343 three weight loss stages may be attributed to the decomposition of the mercaptoacetic acid within 344 the MMA-IONPs modified catalyst.

345 Moreover, the TGA graph showed that the MMA-IONPs catalyst is not stable at $136{ }^{\circ} \mathrm{C}$. The 346 magnetic behaviour of iron oxide nanoparticles and the modified nanoparticles coated with the 347 organic materials can also be observed from the magnetisation measurements at room 348 temperature (Figure 4b). Both samples possess typical superparamagnetic behaviour. The 349 uncoated particles' saturation magnetisation was $85.5 \mathrm{emu} / \mathrm{g}$, and the corresponding value for the 350 modified nanoparticles coated with organic material was $75.5 \mathrm{emu} / \mathrm{g}$. This implies a good 351 distribution of the coated modified nanoparticles onto the iron nanoparticles. The magnetisation 352 of the modified coated nanoparticles was very high as the thickness of the coating material was 353 small due to the short-chain hydrocarbons distributed around the nanoparticles. The nitrogen 354 adsorption-desorption isotherms of $\mathrm{Fe}_{3} \mathrm{O}_{4}$ and $\mathrm{MMA}-\mathrm{Fe}_{3} \mathrm{O}_{4}$ catalysts are shown in Figure 4c. The $355 \mathrm{~S}_{\mathrm{BET}}$ and pore volume of $\mathrm{Fe}_{3} \mathrm{O}_{4}$ were $88.5 \mathrm{~m}^{2} \cdot \mathrm{g}^{-1}$ and $0.11 \mathrm{~cm}^{3} \cdot \mathrm{g}^{-1}$, respectively. While in MMA- 
$356 \mathrm{Fe}_{3} \mathrm{O}_{4}$ catalyst those values dramatically decreased to $13.4 \mathrm{~m}^{2} \cdot \mathrm{g}^{-1}$ and $0.08 \mathrm{~cm}^{3} \cdot \mathrm{g}^{-1}$, respectively 357 which may be due to the attachment of mercaptoacetic acid on the $\mathrm{Fe}_{3} \mathrm{O}_{4}$ support, thus offering 358 another evidence of the successful coating of organic material. The small porous volume of 359 MMA-IONPs is due to the covering of the organic material of the mercaptoacetic acid into the 360 pores of the IONPs support.

361

362

363

364

365

366

367

368

369

370

371

372

373

374

375 


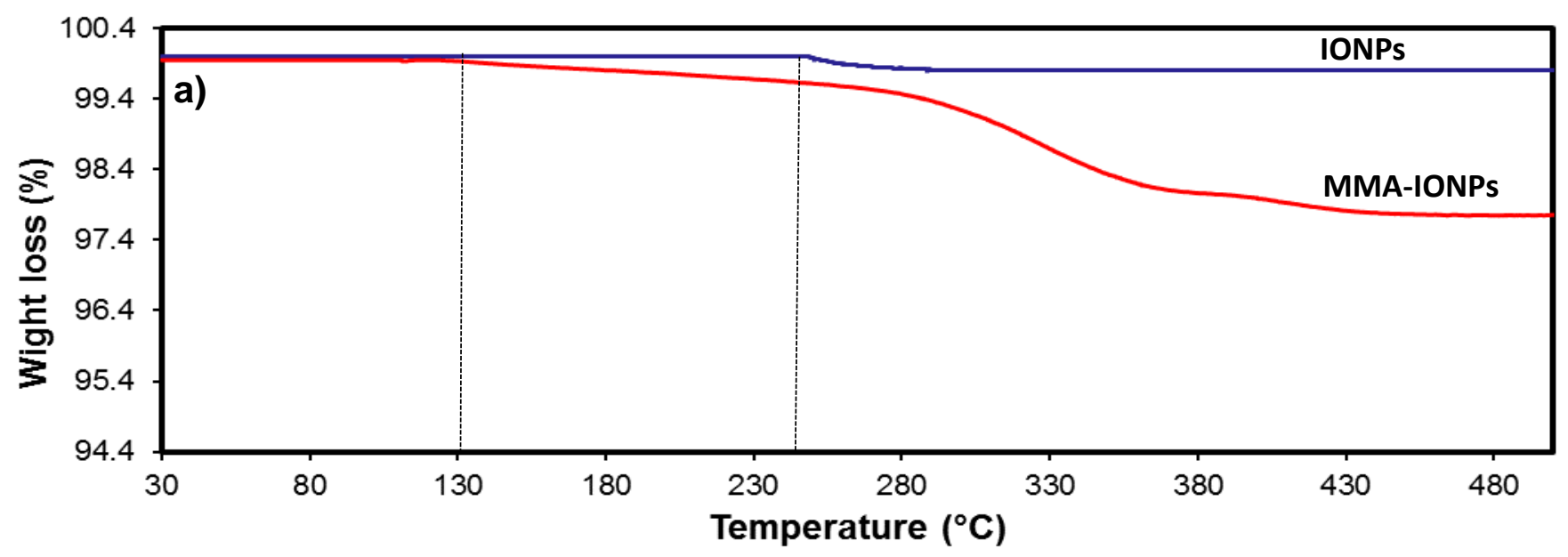

376

377
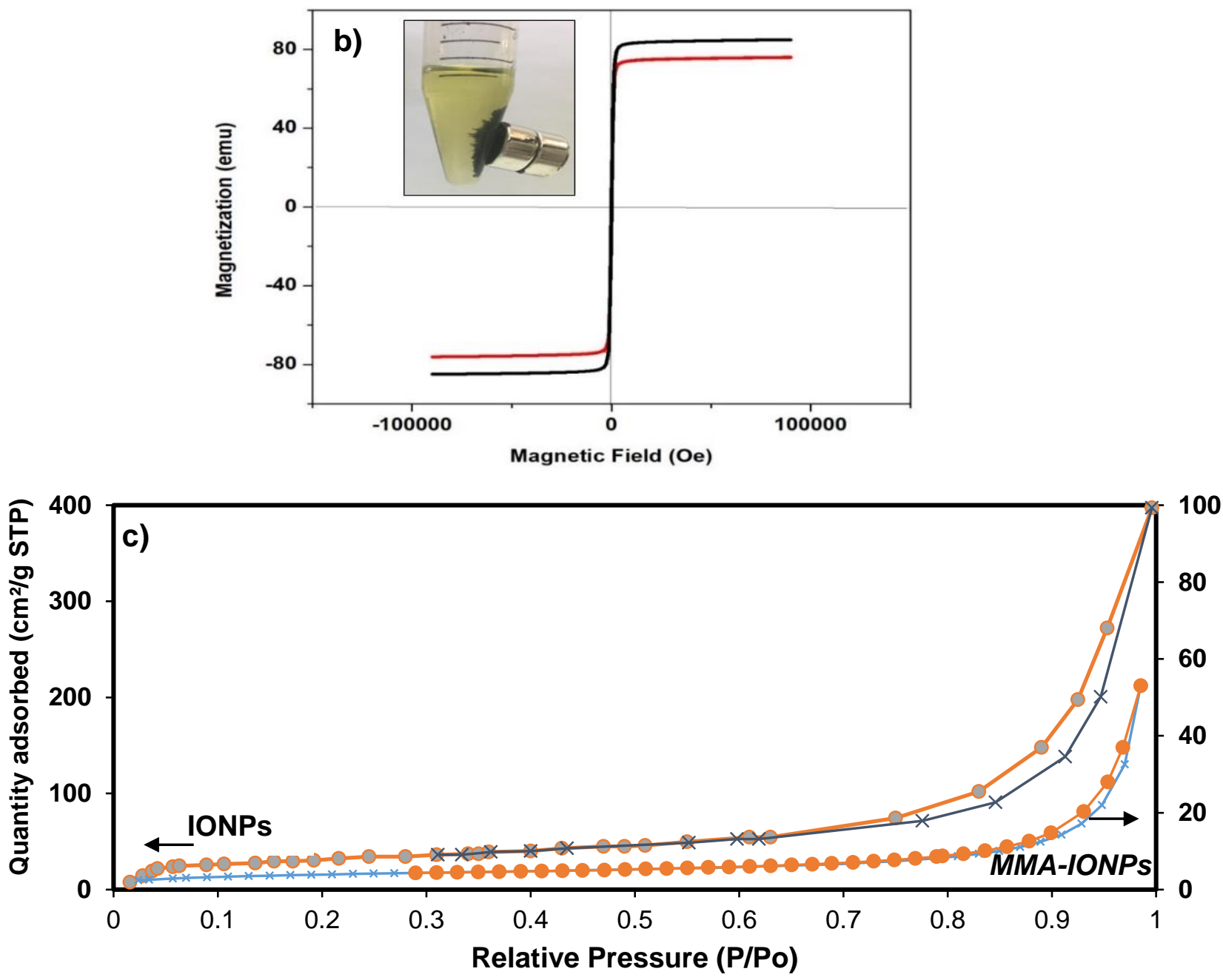

Figure 4: shows a) TGA analysis for IONPs and MMA-IONPs, b) vibrating-sample magnetometer of IONPs and MMA-IONPs along with c) The $\mathrm{N}_{2}$ adsorption-desorption of IONPs and MMA-IONPs catalyst. 
379 It has been reported that methanol is the most suitable alcohol for the esterification process [41]. 380 Esterification was studied herein by varying three parameters, including temperature, residence 381 time and catalyst load within the process to measure their impact on the biodiesel yield 382 (conversion of FFA). The RSM based experimental plan, along with biodiesel yield (which 383 occurs due to FFA and triglycerides conversion) obtained for each experimental test, are reported 384 in Table 1. Moreover, a blank test between methanol and oil was performed and observed to 385 have negligible $(5.3 \% \pm 1.0)$ formation of methyl ester formation. It was noticed that biodiesel 386 yield based on the defined experimental conditions varied from 46 to $91 \mathrm{wt} \%$. The main aim of 387 using RSM was to study the combined effects of process parameters on FFA conversion 388 (biodiesel yield) along with the statistical analysis. Meanwhile, the results related to statistical 389 analysis of extraction process and parametric analysis of FFA conversion based on RSM, are 390 discussed in detail in the following sections.

\subsection{Determination of statistical model}

392 Based on the regression analysis, a reduced quadratic model predicted in terms of coded factors 393 for the response factor (biodiesel yield) was found, as shown in equation 6:

394 Biodiesel Yield $(\%)=0.00122+0.0026 A+0.0002 B-0.0003 C+0.0023 A B-$

395

$0.0012 A C+0.0022 A^{2}+0.0024 A^{2} B$

396 A p-value of less than 0.05 shows the significance of the model at a $95 \%$ confidence level; 397 however, lack of fit should be non-significant for the appropriate model [42]. Lack of fit 398 compares residual error and pure error which should be insignificant for a significant model. 
However, as shown in Table 3, the p-value for the selected model was less than 0.05 , implying that it is significant, with a $95 \%$ confidence level.

Table 3: ANOVA results given by RSM based on which the significance of the predicted model is checked along with each parameter.

\begin{tabular}{|c|c|c|c|c|c|c|}
\hline Source & Sum of & df & Mean Square & F-Value & P-value & \\
\hline Model & 0.00 & 7 & 0.00 & 23.7 & 0.0006 & significant \\
\hline A-t & 0.00 & 1 & 0.00 & 70.2 & 0.0002 & \\
\hline B-T & $2 \times 10^{-7}$ & 1 & $2 \times 10^{-7}$ & 0.4 & 0.5927 & \\
\hline C-S & $6 \times 10^{-7}$ & 1 & $7 \times 10^{-7}$ & 0.9 & 0.3898 & \\
\hline $\mathbf{A B}$ & 0.00 & 1 & 0.00 & 28.9 & 0.0017 & \\
\hline $\mathbf{A C}$ & $5 \times 10^{-6}$ & 1 & $5 \times 10^{-6}$ & 7.3 & 0.0359 & \\
\hline $\mathbf{A}^{\mathbf{2}}$ & 0.00 & 1 & 0.00 & 22.0 & 0.0034 & \\
\hline $\mathbf{A}^{\mathbf{2}} \mathbf{B}$ & 0.00 & 1 & 0.00 & 14.9 & 0.0083 & \\
\hline Residual & $4 \times 10^{-6}$ & 6 & $7 \times 10^{-7}$ & & & \\
\hline Lack of Fit & $4 . \times 10^{-6}$ & 5 & $8.134 \mathrm{E}-07$ & 1.7 & 0.5230 & not significant \\
\hline Pure Error & $5 \times 10^{-7}$ & 1 & $4.801 \mathrm{E}-07$ & & & \\
\hline
\end{tabular}

Analysis of variance (ANOVA) for the experimental data with the predicted model (Table 3). The predicted model was highly significant for this experimental data due to the high F-value of 23.7 and p-value of less than 0.05. A significance can be observed for term A (time of contact) 407 and interactions of variables $\mathrm{AB}$ and $\mathrm{AC}$ and quadratic form of some variable such as $\mathrm{A}^{2}$ and quadratic interaction form such as $\mathrm{A}^{2} \mathrm{~B}$. However, factor $\mathrm{B}$ (temperature) and $\mathrm{C}$ (loading) have 409 less effect as a function of FFA conversion. The coefficient of variation is the ratio of the 410 standard deviation and the mean of data. It is about 6.5, which describes the significant degree of 411 precision with a high reliability of the suggested model's experimental data.

412 Moreover, the coefficient of determination $\left(\mathrm{R}^{2}\right)$ was close to unity, as shown in Table S2. The 413 predicted $\mathrm{R}^{2}$ of 0.8522 is reasonably agreed with the adjusted $\mathrm{R}^{2}$, where the difference is less 
414 than $20 \%$. Besides, adequate precision measures the signal to noise ratio where the ratio greater

415 than 4 is desirable [43]. The suggested model has a ratio of 16.7, which indicates an adequate

416 signal. Table S2 supports the suggestion that the experimental data fit well with the model and

417 provides an estimation of the system's response factors in the range considered.

\section{$418 \quad 3.5$ Effect of operating variables on biodiesel yield}

419 To study the effect of process parameters on biodiesel yield, 3D plots were used which provide 420 the combined effect of two process variables. The combined effect of time of contact and process

421 temperature on the response factor, while catalyst loading was kept constant, as shown in Figure

4225 , was investigated using a 3D plot and 2D contour plot. For both the 3D and 2D contour plots,

423 the time varied between $30 \mathrm{~min}$ to $2 \mathrm{hr}$. The operating temperature ranged from 55 to $65{ }^{\circ} \mathrm{C}$, 424 while catalyst loading was kept constant at $2.5 \mathrm{wt} . \%$ of the pretreated oil weight. The biodiesel 425 yield increased with decreasing the contact time. However, it is important to note that the amount 426 of acid value of date seed oil is not affected directly by the reaction temperature. Thus, when the 427 reaction reached a high temperature at the low contact time, the biodiesel yield was maximised.

428 As the reaction temperature increased near the alcohol boiling point, the reaction mixture tends 429 to be in one phase (methanol/oil), and the conversion was maximised. The curvilinear nature of $4303 \mathrm{D}$ and 2D contour plots depicts the significance of an interactive effect on biodiesel yield as the 431 maximum value of the response factor was found at a lower time of contact. 


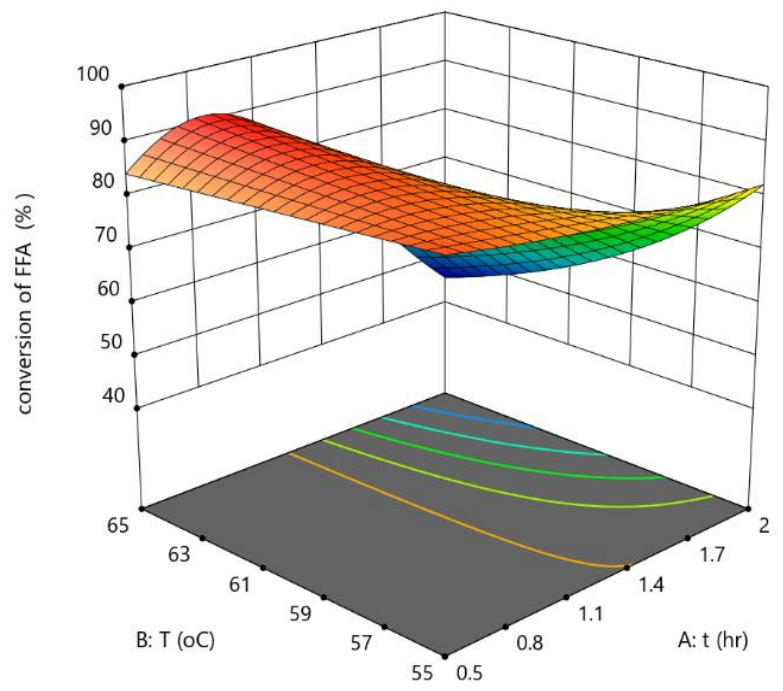

432

433

$434 \quad$ Figure 5: 3D and contour 2D plots for analysing the combined effect of contact time and process temperature on the FFA conversion (biodiesel yield) of date seed oil.

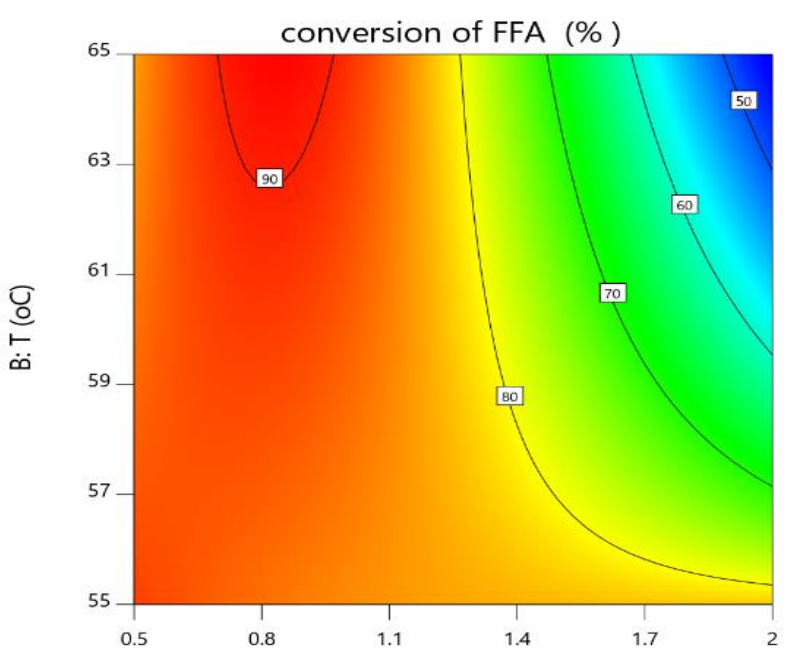

A: $t(h r)$

437 The interactive effect of time of contact (0.5-2 hr.) and catalyst loading (1.5-3.5 wt.\% of oil 438 weight) on the value of biodiesel yield when the temperature was kept constant $\left(65^{\circ} \mathrm{C}\right)$ is shown 439 in Figure 6 by 3D and 2D contour plots. It is obvious that as the time of contact increases, the 440 biodiesel yield decreases. On the one hand, at low catalyst loadings along with low contact time, 441 this scenario can maximise the biodiesel yield. In contrast, the high catalyst loading provided 442 high biodiesel yield of approximately $85 \mathrm{wt} . \%$, when the time contact was low. Thus, the acid 443 value was reduced to $2 \mathrm{mg} \mathrm{KOH} / \mathrm{g}$ of oil at a low catalyst loading with low reactions occurring. 

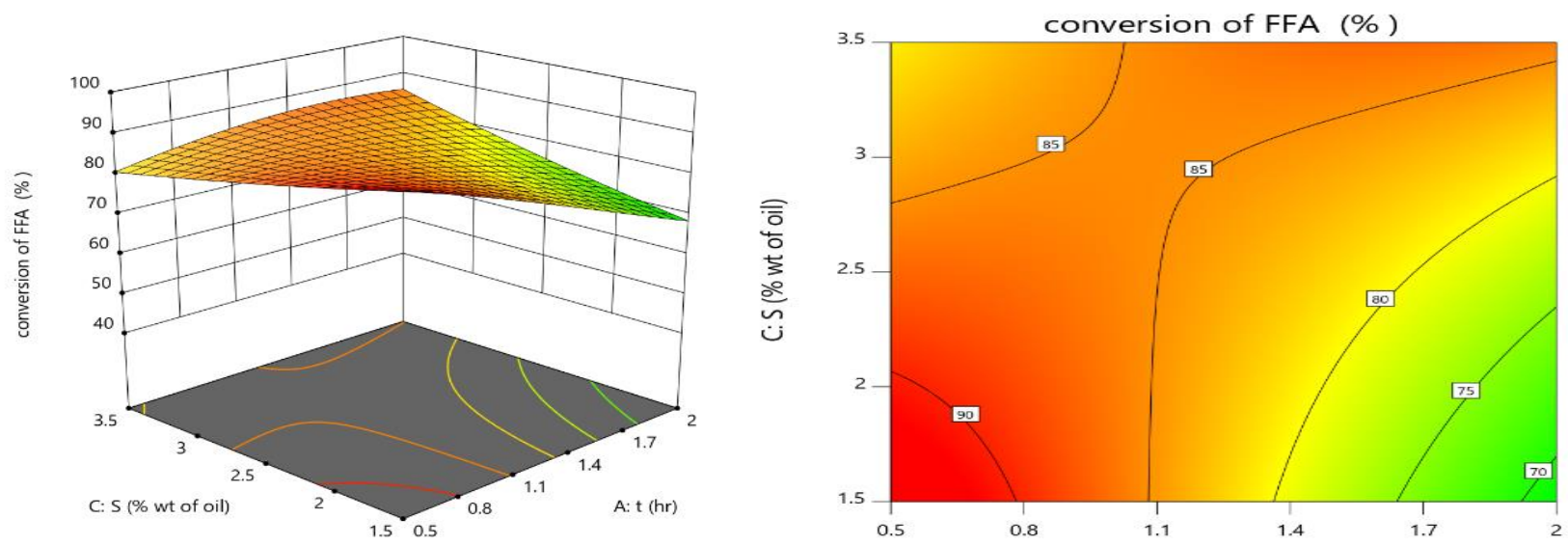

Figure 6: 3D and contour 2D plots for analysing the combined effect of contact time and catalyst loading on the FFA conversion (biodiesel yield) of date seed oil.

444 The optimisation condition that can maximise the biodiesel yield of date seed oil, minimise the

445 operating temperature and minimising the catalyst loading are shown in Figure 7. This operating

446 condition was used to investigate the activity of the catalyst. The optimum time, temperature and

447 catalyst loading was $0.7 \mathrm{hr} ., 55{ }^{\circ} \mathrm{C}$ and $1.5 \mathrm{wt} . \%$ of pretreated oil, while the biodiesel yield was

$44890 \%$. The optimum conditions for the esterification reaction using the MMA-IONPs had lower

449 catalyst loading, contact time and operating temperature than other catalysts. Moreover, the

450 percentage conversions of FFA were high in both MMA-IONPs and Al-SA catalysts with values

451 of $90,92.6 \%$, respectively. 


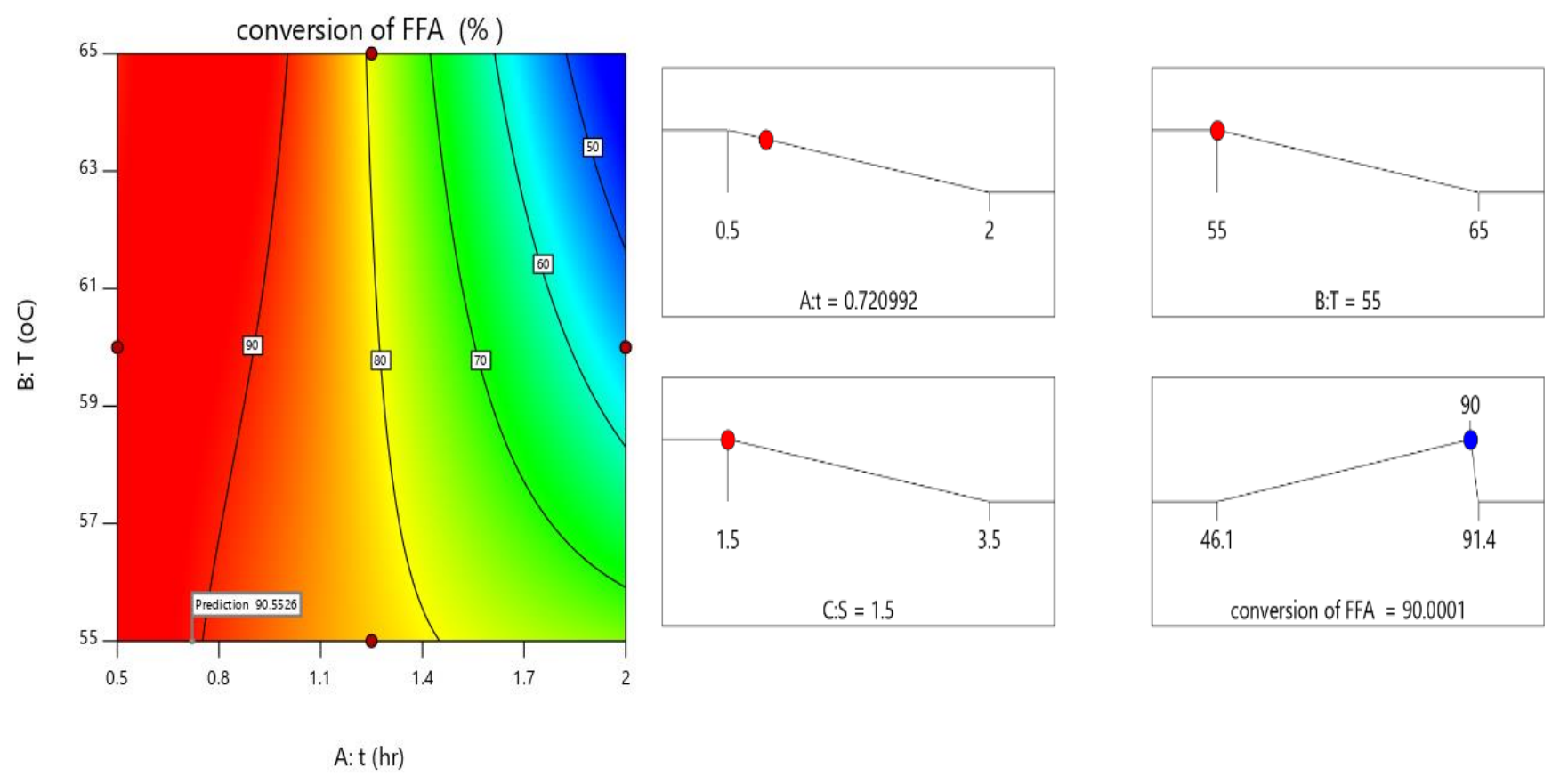

Figure 7: optimisation condition of all parameter for high FFA conversion.

\subsection{Catalyst reusability and activity}

455 Reusability of catalysts is a crucial characteristic when considering upscaling the process on the 456 industrial scale. MMA-IONPs catalysts' reusability was determined based on the optimal set of 457 conditions such as temperature $55^{\circ} \mathrm{C}$, time $42 \mathrm{~min}$., catalysts loading $1.5 \mathrm{wt} \%$ and methanol to 458 oil ratio 15:1. Esterification of free fatty acids was performed repeatedly for five times, as shown 459 in Figure 8. After each run, the catalyst was recovered, rinsed with ethanol to remove the 460 remaining organic components followed by water washing and then to dry in a vacuum oven at $46160{ }^{\circ} \mathrm{C}$ for $12 \mathrm{hrs}$. The catalyst's reusability revealed that the MMA-IONPs catalyst is to maintain 462 its catalytic activity for five times without any significant decrease in the biodiesel yield. Based 463 on the FTIR spectrum analysis, the catalyst was active with the origin catalyst's same absorption 464 bands, as shown in Figure S4. 


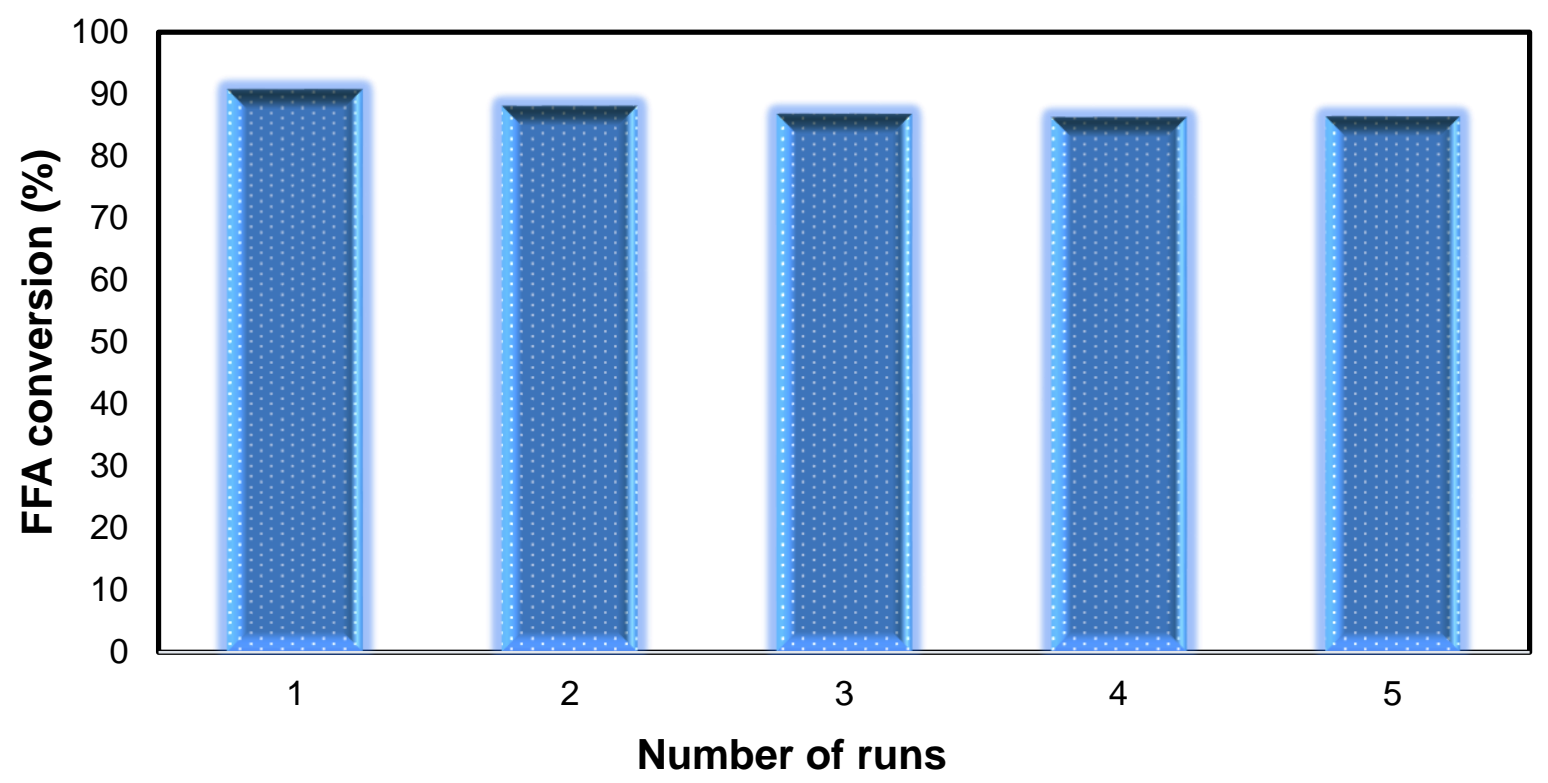

466 Figure 8: Reusability of synthesised catalyst for FFA conversion (biodiesel yield) on an 467 optimised set of conditions for esterification.

\section{$468 \quad 3.7$ Life cycle assessment}

\section{$469 \quad$ 3.7.1 Goal and scope}

470 The goal of using LCA in the current study was to evaluate environmental and human health

471 impacts of biodiesel product from date seed oil, considering the guidelines provided by ISO:

47214040 and ISO: 14044 [28, 44]. The functional unit in this study is $1000 \mathrm{~kg}$ of biodiesel

473 produced using date seeds as raw material. The LCA system boundary consisted of raw material

474 transportation, raw material preparation for date seeds to date seed oil, catalyst preparation and 475 reuse, and esterification for biodiesel preparation (Figure 9). The waste products from the system 476 included gaseous emissions, wastewater and solid cake for which the impacts were not 477 considered. 


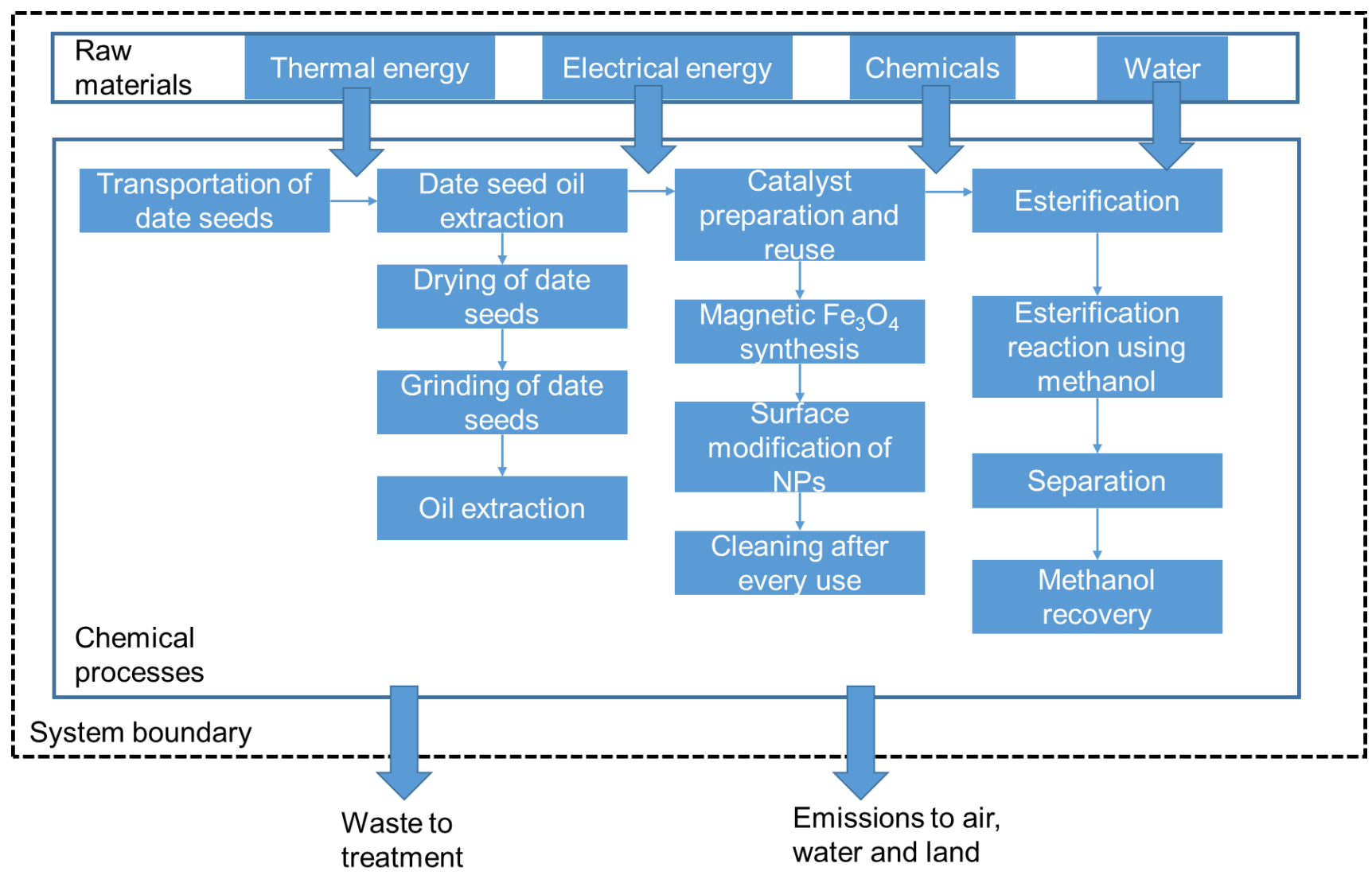

Figure 9: System boundary for life cycle analysis of biodiesel production.

\subsubsection{Inventory analysis}

This LCA has a cradle-to-gate attributional approach and did not include any infrastructure

482 processes related to lab equipment production. The production of date seeds was not considered

483 part of the system boundary, as it was a waste source. The raw material transportation for 200

$484 \mathrm{~km}$ was considered in the present study from farms to the oil extraction centre for date seeds

485 (Table 4). Prior to oil preparation, date seeds were dried, and the energy requirement was

486 adapted from operating parameters of the instrument. However, the present study applied soxhlet

487 extraction, as date seed oil was used for conversion in the laboratory. That said, large-scale

488 processing of date seed oil to produce biodiesel would benefit from an application of commercial

489 processes including drying, cooking of seeds, conversion of date seeds to flakes and expeller, 
490 with energy requirements from instrument operating conditions and Fridrihsone et al. [45].

491 However, only $10 \%$ efficiency was considered from this process, as generally the extraction

492 without solvents is less efficient. No weight loss was considered during the cooking of seeds.

493 In addition to biodiesel production using date seed oil, catalyst preparation and reuse were also

494 considered part of the LCA subsystem. It was observed that the best yield of date seed oil was at $4951.5 \mathrm{wt} \%$ of catalyst for date seed oil (Section 3.5) Accordingly, producing $1000 \mathrm{~kg}$ of biodiesel 496 requires $3 \mathrm{~kg}$ of a catalyst by reusing the same catalyst four times. The precursor mass 497 requirement was referred from the catalyst preparation process (Section 2.2). It was assumed that 498 the surface coating of NPs does not lead to a change in molecular weight. Moreover, the 499 wastewater and ethanol mixture were used to clean the catalyst after use, for $1 \mathrm{~kg}$ of catalyst 500 cleaned 11 of water and ethanol mixture to be utilised. After considering losses of cleaning 501 mixture (10\%), this process led to the production of wastewater [46]. Moreover, electrical energy 502 requirements were considered from Marimón-Bolívar and González [47]. Additionally, the 503 location of the catalyst preparation unit was considered to be in the vicinity of the biodiesel 504 production plant, and thus the transportation of catalyst was not considered as part of LCA.

505 The feedstocks for esterification included methanol, catalyst and date seed oil. The findings from 506 the experiments showed the use of methanol: oil as 15:1 and 1.5 wt\% of oil as a catalyst (section 507 3.6). The required energy for carrying out esterification was referred from Dufour and Iribarren 508 [48]. The amount of catalyst at the end of the reaction was assumed to be constant as no catalyst 509 consumption was assumed in the reaction. Moreover, the present study showed an efficiency of $51090 \%$ for oil to biodiesel conversion. Therefore, $1111.11 \mathrm{~kg}$ of date seed oil and $15 \mathrm{~kg}$ of catalyst 511 (3 $\mathrm{kg}$ used four times) and $74.07 \mathrm{~kg}$ of methanol lead to biodiesel production (1000.00 kg). The 512 methanol losses were considered due to evaporation. 
513 Moreover, there was the energy required for separation, filtration and centrifugation, which was

514 considered to be $2 \%$ of the esterification process. The material losses due to the use of filters

515 were neglected in the LCA process. Recovery of methanol and corresponding energy

516 requirements were calculated using Eq. 7 and 8, according to Barjoveanu et al. [49].

$517 \quad \mathrm{Qa}=\mathrm{m} . \mathrm{Cp} \cdot \Delta \mathrm{T}$

$518 \mathrm{Qm}=$ hc. A. $\Delta \mathrm{T}$

519 where, Qa is the energy required for heating ( $k W h), Q m$ is the energy for maintaining required 520 temperature $(\mathrm{kWh}), \mathrm{m}$ is the mass of heated fluid $(\mathrm{kg}), \mathrm{Cp}$ is the specific heat, $(\mathrm{kW} / \mathrm{kg} \mathrm{K}), \mathrm{hc}$ is 521 the global heat transfer coefficient, $\left(W / m^{2} K\right), A$ is the heated surface area, $\Delta T$ is the temperature

522 difference (degrees).

523 Table 4: Inventory analysis for LCA of production of $1000 \mathrm{~kg}$ of biodiesel.

\begin{tabular}{|c|c|c|c|c|}
\hline Inventory item & Unit & Input & Output & Reference \\
\hline \multicolumn{5}{|l|}{ Raw material transportation } \\
\hline Diesel & $\mathrm{kg}$ & & & \\
\hline a Transportation & $\mathrm{tkm}$ & & 2777.78 & Based on calculation $(\mathrm{t} * \mathrm{~km})$ \\
\hline \multicolumn{5}{|l|}{ Oil extraction } \\
\hline${ }^{b}$ Electricity for drying seeds & kwh & 30.72 & & $\begin{array}{l}\text { Instrument [50] (Drying } \\
\text { oven) }\end{array}$ \\
\hline Electricity for cooking seeds & kwh & 138.75 & & Instrument [51] \\
\hline Electricity for seed flaker & kwh & 77.76 & & Instrument [52] \\
\hline Electricity for oil extraction & kwh & 503.64 & & {$[45]$} \\
\hline Date seeds & $\mathrm{kg}$ & 13888.88 & & \multirow{5}{*}{$\begin{array}{l}\text { Oil extraction process } \\
\text { (Section } 2.1 \text { ) }\end{array}$} \\
\hline Dried date seeds & $\mathrm{kg}$ & & 11111.1 & \\
\hline Solid cake & $\mathrm{kg}$ & & 8666.66 & \\
\hline Loss & $\mathrm{kg}$ & & 222.22 & \\
\hline Date seed oil & $\mathrm{kg}$ & & 1111.11 & \\
\hline \multicolumn{5}{|l|}{ Catalyst preparation and reuse } \\
\hline 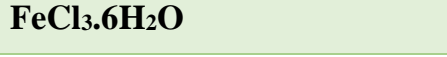 & $\mathrm{kg}$ & 10.51 & & \multirow{2}{*}{$\begin{array}{l}\text { Catalyst preparation process } \\
\text { (Section } 2.2 \text { ) }\end{array}$} \\
\hline Sodium acetate & $\mathrm{kg}$ & 22.38 & & \\
\hline
\end{tabular}




\begin{tabular}{|c|c|c|c|c|}
\hline Ethylene glycol & 1 & 194.63 & & \\
\hline Mercaptoacetic acid & 1 & 37.5 & & \\
\hline Ethanol $(50 \%$ v/v) & $\mathrm{kg}$ & 0.001 & & \\
\hline Electricity for synthesis & kwh & 138.00 & & \multirow{2}{*}{$\begin{array}{l}\text { Marimón-Bolívar and } \\
\text { González (2018) [47] }\end{array}$} \\
\hline c Thermal energy for synthesis & MJ & 138.00 & & \\
\hline Catalyst & $\mathrm{kg}$ & & 3.00 & \\
\hline${ }^{d}$ Catalyst reuse for four runs & $\mathrm{kg}$ & & 12.00 & \multirow{3}{*}{$\begin{array}{l}\text { Catalyst reuse process } \\
\text { (Section 3.6) }\end{array}$} \\
\hline Water & 1 & 6 & & \\
\hline Ethanol & 1 & 6 & & \\
\hline Wastewater & 1 & & 10.80 & Chung et al. (2019) [53] \\
\hline Electricity for drying & kwh & 2.48 & & Instrument operation [50] \\
\hline \multicolumn{5}{|l|}{ Esterification } \\
\hline Date seed oil & $\mathrm{kg}$ & 1111.11 & & $\begin{array}{l}\text { Esterification reactions } \\
\text { (Section } 3.5 \text { ) }\end{array}$ \\
\hline Methanol & $\mathrm{kg}$ & 74.07 & & \\
\hline Thermal energy for esterification & MJ & 222.30 & & \multirow{2}{*}{$\begin{array}{l}\text { Dufour and Iribarren (2012) } \\
\text { [48] }\end{array}$} \\
\hline Electricity for esterification & $\mathrm{kWh}$ & 31.43 & & \\
\hline${ }^{\mathrm{e}}$ Biodiesel & $\mathrm{kg}$ & & 1000.00 & \\
\hline Electricity for separation & $\mathrm{kWh}$ & 0.06 & & \multirow[t]{2}{*}{$2 \%$ of esterification energy } \\
\hline Thermal energy for separation & $\mathrm{MJ}$ & 4.44 & & \\
\hline Methanol recovered $(95 \%)$ & $\mathrm{kg}$ & & 70.37 & \\
\hline Electricity for methanol recovery & kwh & 91.3 & & Eq. 7 and 8 \\
\hline
\end{tabular}

${ }^{a}$ Transportation: Lorry transport, Euro 0, 1, 2, 3, 4 mix, 22 t total weight, 17,3 t max payload 525 RER

$526{ }^{b}$ Electricity, production mix PK (WFLDB 3.1)/PK $U$

$527{ }^{c}$ Calorific value of natural gas: $42 \mathrm{MJ} / \mathrm{kg}$

$528{ }^{d}$ Total consecutive use of catalyst was considered for five runs (reuse for four runs).

$529{ }^{e}$ Biodiesel calorific value: $41.39 \mathrm{MJ} / \mathrm{kg}$

$530 \quad$ 3.7.3 Midpoint indicator assessment

531 In this study, midpoint indicator assessment was conducted using CML-IA baseline V3.06 to

532 better understand and compare the impact categories. LCA of the biodiesel production process

533 was conducted based on four stages in the inventory analysis: raw material transportation, oil

534 extraction, catalyst preparation and reuse, and esterification to produce $1000 \mathrm{~kg}$ of biodiesel (1 
535 functional unit). The waste treatment processes and emissions to air, water and land were not

536 considered as part of LCA, as shown in system boundary in Figure 9.

537 Table 5 shows the results of the midpoint indicator assessment. Esterification showed the least 538 environmental impacts followed by raw material transportation. This is due to the distance 539 consideration of $200 \mathrm{~km}$ in the present study.

540 Table 5. Environmental impacts due to biodiesel production process (1000 kg) computed using 541 CML-IA baseline V3.06.

\begin{tabular}{|c|c|c|c|c|c|}
\hline Impact category & Unit & $\begin{array}{l}\text { Raw material } \\
\text { transportation }\end{array}$ & Oil extraction & $\begin{array}{l}\text { Catalyst preparation } \\
\text { and }{ }^{\text {a }} \text { reuse }\end{array}$ & Esterification \\
\hline Abiotic depletion & kg Sb eq & 0.00 & 0.00 & 0.02 & 0.00 \\
\hline $\begin{array}{l}\text { Abiotic depletion } \\
\text { (fossil fuels) }\end{array}$ & MJ & 1282.11 & 2439.34 & 14503.26 & 812.09 \\
\hline $\begin{array}{l}\text { Global warming } \\
\text { (GWP100a) }\end{array}$ & $\mathrm{kg} \mathrm{CO}_{2}$ eq & 91.53 & 247.74 & 726.80 & 48.18 \\
\hline $\begin{array}{l}\text { Ozone layer } \\
\text { depletion (ODP) }\end{array}$ & kg CFC-11 eq & 0.00 & 0.00 & 0.00 & 0.00 \\
\hline Human toxicity & kg 1,4-DB eq & 2.86 & 119.44 & 489.70 & 20.96 \\
\hline $\begin{array}{l}\text { Fresh water } \\
\text { aquatic ecotox. }\end{array}$ & kg 1,4-DB eq & 0.05 & 161.06 & 324.89 & 26.69 \\
\hline $\begin{array}{l}\text { Marine aquatic } \\
\text { ecotoxicity }\end{array}$ & kg 1,4-DB eq & 1222.86 & 472924.54 & 834714.31 & 78797.35 \\
\hline $\begin{array}{l}\text { Terrestrial } \\
\text { ecotoxicity }\end{array}$ & kg 1,4-DB eq & 0.00 & 0.35 & 0.90 & 0.06 \\
\hline $\begin{array}{l}\text { Photochemical } \\
\text { oxidation }\end{array}$ & $\mathrm{kg} \mathrm{C}_{2} \mathrm{H}_{4} \mathrm{eq}$ & 0.03 & 0.05 & 0.38 & 0.01 \\
\hline Acidification & $\mathrm{kg} \mathrm{SO}{ }_{2}$ eq & 0.43 & 1.37 & 3.07 & 0.26 \\
\hline Eutrophication & $\mathrm{kg} \mathrm{PO}_{4}^{---}$eq & 0.10 & 1.04 & 1.12 & 0.17 \\
\hline
\end{tabular}

$542 \quad$ [ Catalyst reuse was considered for four runs]

543 For oil extraction on a commercial scale, depletion of fossil fuels (2439.34 MJ) and global

544 warming potential (247.74 $\left.\mathrm{kg} \mathrm{CO}_{2} \mathrm{eq}\right)$ were observed. The catalyst preparation and reuse for four

545 cycles showed abiotic depletion of fossil fuels as 14503.26 MJ and global warming potential as

$546726.8 \mathrm{~kg} \mathrm{CO}_{2}$ eq. This is due to high electricity input for catalyst preparation. The final stage 
547 evaluated for LCA was esterification to produce biodiesel. This stage's inputs were date seed oil,

548 catalyst, methanol, and electricity, leading to depletion of fossil fuels as 812.09 MJ.

549 Relative results were generated from the simulation for which indicator results maximum is set $550100 \%$. Figure 10 shows that catalyst preparation and reuse are above all other processes in terms 551 of impact categories. This is due to energy use in thermal and electricity forms, leading to 552 emissions related to energy production and use. It is also worth noticing that the catalyst use was 553 only considered for five consecutive times in total (i.e., reuse for four runs), in accordance with 554 reusability data in Section 3.6; however, in a more realistic scenario during the use of magnetic 555 catalysts in industrial applications, this reuse will be performed many times. This will lead to a 556 further reduction of environmental impacts.

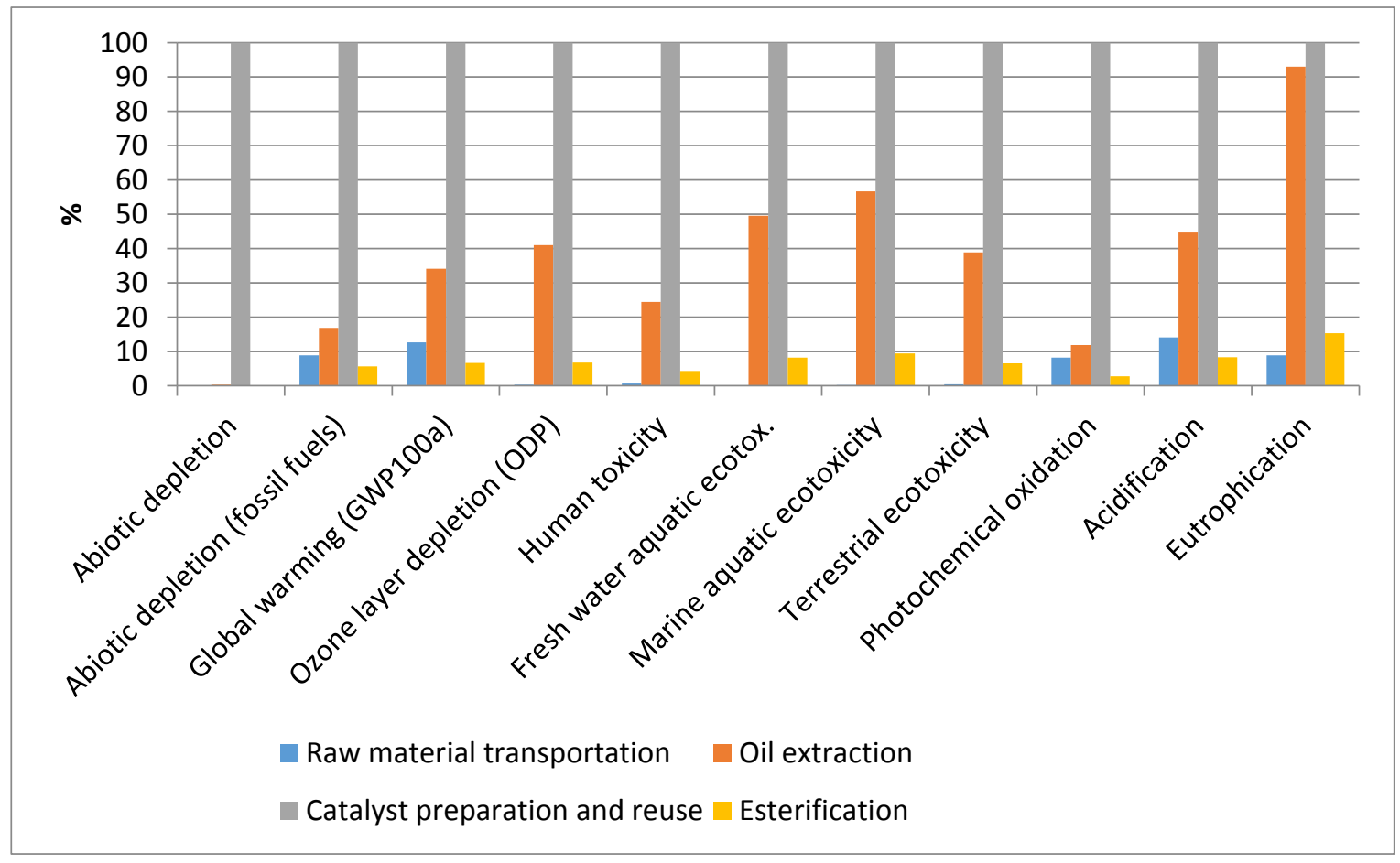

Figure 10: CML-IA baseline V3.06 midpoint indicators for $1000 \mathrm{~kg}$ of biodiesel production 559 using waste date seed oil. [Note: Catalyst reuse was considered for four runs] 


\subsubsection{Endpoint indicator assessment}

ReCiPe 2016 Endpoint (E) V1.04 was used to conduct endpoint analysis. Table 6 shows endpoint indicator assessment for the overall process, including human health, ecosystem quality and resources. Ecosystem quality comprises of acidification, ecotoxicity, eutrophication and land use. Regarding human health, it is related to the impacts of environmental degradation that increases of, and duration of loss-of-life-years related diseases. Whilst for resources, it is closely related to the depletion rate of raw materials and energy sources. Agricultural resource depletion in the form of land-use change is not considered as date seeds do not require plantation due to their source from waste. Results are evaluated based on the future energy surplus requirements needed to produce lower-quality energy and minerals. The findings obtained from the endpoint impact assessment are in accordance with midpoint indicator impact assessment (Table 6), with transportation, being the least contributor to damage to ecosystems and human health.

Table 6. Environmental impacts due to biodiesel production process (1000 $\mathrm{kg}$ ) computed using ReCiPe 2016 Endpoint (E) V1.04.

\begin{tabular}{|c|c|c|c|c|c|}
\hline $\begin{array}{c}\text { Damage } \\
\text { category }\end{array}$ & Unit & $\begin{array}{c}\text { Raw material } \\
\text { transportation }\end{array}$ & $\begin{array}{c}\text { Oil } \\
\text { extraction }\end{array}$ & $\begin{array}{c}\text { Catalyst } \\
\text { preparation } \\
\text { and }^{\text {a }} \text { reuse }\end{array}$ & Esterification \\
\hline $\begin{array}{c}\text { Human } \\
\text { health }\end{array}$ & DALY & 0.001 & 0.024 & 0.045 & 0.004 \\
\hline Ecosystems & species.yr & $2.4563 \times 10^{-6}$ & $1.513 \times 10^{-5}$ & $3.440 \times 10^{-5}$ & $2.632 \times 10^{-6}$ \\
\hline Resources & USD2013 & 12.599 & 11.223 & 117.482 & 4.182 \\
\hline
\end{tabular}

575 $\left[{ }^{\mathrm{a}}\right.$ Catalyst reuse was considered for four runs]

576 The cumulative human health, ecosystems and resources impact over the entire process were 577 observed as $330.45 \mathrm{Pt}, 25.92 \mathrm{Pt}$, and $1.04 \mathrm{Pt}$, respectively (Figure 11). LCA's overall results 578 show that $19037 \mathrm{MJ}$ of energy was required to produce biofuel quantities of $1000 \mathrm{~kg}$ (1 579 functional unit) with a calorific value of $41.39 \mathrm{MJ} / \mathrm{kg}$. Thus, the energy ratio computed using 580 output as $41390 \mathrm{MJ}$ shows an energy ratio of 2.17 , which is in close range with the energy ratio 581 for palm oil biodiesel reported by Pleanjai and Gheewala [54] as 3.15. Moreover, $1.11 \mathrm{~kg} \mathrm{CO}_{2}$ 
$582 \mathrm{eq} / \mathrm{kg}$ of carbon emissions, took place due to date seed oil biodiesel in the present study, which is

583 comparable with palm oil biodiesel as $1.07 \mathrm{~kg} \mathrm{CO}$ eq/kg. Nevertheless, it should be noted that

584 date seed biodiesel produced in the present study was from a waste-derived feedstock and

585 catalyst was used for a total of five runs. While palm oil is produced using agricultural

586 plantations [54], which leads to drastic environmental concerns due to land-use change.

587 Therefore, the present study demonstrated that even when specific energy crops are not utilised

588 for biodiesel production, the energy ratio and carbon emissions can be comparable.

\begin{tabular}{|c|c|c|c|c|}
\hline \multirow{12}{*}{$\begin{array}{l}\text { 릉 } \\
\text { م }\end{array}$} & \multicolumn{4}{|l|}{200.00} \\
\hline & \multicolumn{4}{|l|}{180.00} \\
\hline & \multicolumn{4}{|l|}{160.00} \\
\hline & \multicolumn{4}{|l|}{140.00} \\
\hline & \multicolumn{4}{|l|}{120.00} \\
\hline & \multicolumn{4}{|l|}{100.00} \\
\hline & \multicolumn{4}{|l|}{80.00} \\
\hline & \multicolumn{4}{|l|}{60.00} \\
\hline & \multicolumn{4}{|l|}{40.00} \\
\hline & \multicolumn{4}{|l|}{20.00} \\
\hline & \multirow[t]{2}{*}{0.00} & \multicolumn{3}{|c|}{ 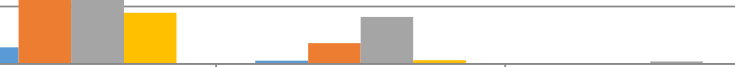 } \\
\hline & & $\begin{array}{c}\text { Human } \\
\text { health }\end{array}$ & Ecosystems & Resources \\
\hline$\square \mathrm{R}$ & isportation & 5.83 & 1.17 & 0.09 \\
\hline-0 & & 106.93 & 7.18 & 0.08 \\
\hline C & ion and & 199.81 & 16.32 & 0.84 \\
\hline$E$ & & 17.88 & 1.25 & 0.03 \\
\hline
\end{tabular}

590 Figure 11: ReCiPe 2016 Endpoint (E) V1.04 endpoint indicators for producing $1000 \mathrm{~kg}$ of 591 biodiesel using date seed oil.

592 [Note: Catalyst reuse was considered for four runs] 


\section{Conclusion}

594 Upcycling biomass waste into sustainable energy sources following a circular bioeconomy 595 approach has two-fold benefits: (1) mitigation of waste management issues; and (2) to provide 596 renewable energy sources. Biodiesel production through transesterification needs a specific acid 597 value of bio-oil to increase the biodiesel yield, so an acidic heterogeneous catalyst was 598 synthesised and used for converting the free fatty acids contained in the waste date seed oil into 599 biodiesel. The mercaptoacetic acid supported on iron oxide nanoparticles was used as a magnetic 600 solid acid catalyst herein. The esterification reaction was optimised by considering the 601 temperature, time and catalyst loading to increase the percentage of FFAs conversion (biodiesel 602 yield). The optimised FFAs conversion was $90 \%$ when the temperature was $55^{\circ} \mathrm{C}$, time 47 min., 603 and catalyst loading 1.5 wt.\% of pretreated oil. Statistical analysis ANOVA was also used, which 604 indicated that the suggested mathematical model was in good agreement with experimental data. 605 The significance of the model was checked from its p-value, less than 0.05, which shows its 606 significance. Furthermore, the FFA conversion (biodiesel yield) calculated using the predicted 607 model was in good agreement with the actual yield obtained from experiments.

608 The LCA results by using midpoint indicators for $1000 \mathrm{~kg}$ of biodiesel production (1 Functional 609 unit) showed the cumulative abiotic depletion of fossil resources over all the processes as $61018740.2 \mathrm{MJ}$, global warming potential as $1084.13 \mathrm{~kg} \mathrm{CO}_{2} \mathrm{eq}$, and human health toxicity as $611618.45 \mathrm{~kg} \mathrm{1,4-DB}$ eq ( $\mathrm{kg} \mathrm{1,4}$ dichlorobenzene eq). The highest damage in all categories was 612 observed during catalyst preparation and reuse for four runs. This was confirmed in endpoint 613 LCA findings (ReCiPe 2016 Endpoint (E) V1.04), where catalyst preparation and reuse for four 614 runs contributed impacts to human health $(199.81 \mathrm{Pt})$, ecosystems damage (16.32 Pt) and 615 resources depletion $(0.84 \mathrm{Pt})$. The cumulative human health, ecosystems and resources impact 
616 over the entire process were observed as $330.45 \mathrm{Pt}, 25.92 \mathrm{Pt}$, and $1.04 \mathrm{Pt}$ respectively. The

617 energy ratio for the entire process was computed as 2.17 and carbon emissions as $1.11 \mathrm{~kg} \mathrm{CO}_{2}$

$618 \mathrm{eq} / \mathrm{kg}$.

619 The utilisation of waste date seeds in biodiesel production helps address the growth of the

620 circular bioeconomy by upcycling an otherwise waste and problematic thermochemical

621 conversion feedstock by adding value and providing potential routes for application in the energy

622 sector.

623 Acknowledgment:

624 The authors would like to thank Sultan Qaboos University and the College of Engineering for 625 their support during this work. Ahmed Osman and David Rooney would like to acknowledge the 626 support given by the EPSRC project "Advancing Creative Circular Economies for Plastics via 627 Technological-Social Transitions" (ACCEPT Transitions, EP/S025545/1) and the support of The 628 Bryden Centre project (Project ID VA5048) which was awarded by The European Union's 629 INTERREG VA Programme, managed by the Special EU Programmes Body (SEUPB), with 630 match funding provided by the Department for the Economy in Northern Ireland and the 631 Department of Business, Enterprise and Innovation in the Republic of Ireland.

\section{Disclaimer}

633 The views and opinions expressed in this paper do not necessarily reflect those of the European 634 Commission or the Special EU Programmes Body (SEUPB).

635 Competing interests: The authors declare no competing interests. 
638 [1] P. Stegmann, M. Londo, M. Junginger, The circular bioeconomy: Its elements and role in European bioeconomy clusters, Resources, Conservation \& Recycling: X 6 (2020) 100029. [2] Konstantinos P. Tsagarakis, loannis Nikolaou, F. Konstantakopoulou, Circular Economy, Ethical Funds, and Engineering Projects, https://doi.org/10.3390/books978-3-03928-253-1, Sustainability ISBN 978-303928-252-4 (Pbk); ISBN 978-3-03928-253-1 (PDF) (2020) 1-300.

643 [3] M.A. Amani, M.S. Davoudi, K. Tahvildari, S.M. Nabavi, M.S. Davoudi, Biodiesel production from Phoenix dactylifera as a new feedstock, Industrial Crops and Products 43 (2013) 40-43.

[4] M.W. Azeem, M.A. Hanif, J.N. Al-Sabahi, A.A. Khan, S. Naz, A. ljaz, Production of biodiesel from low priced, renewable and abundant date seed oil, Renewable energy 86 (2016) 124-132.

[5] K. Krisnangkura, A simple method for estimation of cetane index of vegetable oil methyl esters, Journal of the American Oil Chemists' Society 63(4) (1986) 552-553.

649

[6] L. Meher, D.V. Sagar, S. Naik, Technical aspects of biodiesel production by transesterification-a review, Renewable and sustainable energy reviews 10(3) (2006) 248-268.

[7] F. Ma, M.A. Hanna, Biodiesel production: a review, Bioresource technology 70(1) (1999) 1-15.

653

654

655

656

657

658

659

660

661

662

663

664

665

666

667

668

669

670

671

672

[8] S. Pasias, N. Barakos, C. Alexopoulos, N. Papayannakos, Heterogeneously catalyzed esterification of FFAs in vegetable oils, Chemical Engineering \& Technology: Industrial Chemistry-Plant Equipment-Process Engineering-Biotechnology 29(11) (2006) 1365-1371.

[9] S. Fawzy, A.I. Osman, J. Doran, D.W. Rooney, Strategies for mitigation of climate change: a review, Environmental Chemistry Letters 18(6) (2020) 2069-2094.

[10] A.I. Osman, M. Hefny, M.I.A. Abdel Maksoud, A.M. Elgarahy, D.W. Rooney, Recent advances in carbon capture storage and utilisation technologies: a review, Environmental Chemistry Letters (2020).

[11] L. Lin, Z. Cunshan, S. Vittayapadung, S. Xiangqian, D. Mingdong, Opportunities and challenges for biodiesel fuel, Applied energy 88(4) (2011) 1020-1031.

[12] M.A. Al-Farsi, C.Y. Lee, Optimization of phenolics and dietary fibre extraction from date seeds, Food Chemistry 108(3) (2008) 977-985.

[13] S. Besbes, C. Blecker, C. Deroanne, G. Lognay, N.-E. Drira, H. Attia, Heating effects on some quality characteristics of date seed oil, Food chemistry 91(3) (2005) 469-476.

[14] F. Jamil, Valorization of Omani waste Date (Phoenix Dactylifera) pits for production of biofuels Petroleum and Chemical Engineering Sultan Qaboos University Sultanate of Oman 2017, p. 254.

[15] A.T. Madsen, R. Fehrmann, Catalytic Production of Biodiesel, Centre for Catalysis and Sustainable Chemistry (2011).

[16] A.M. Abu-Jrai, F. Jamil, H. Ala'a, M. Baawain, L. Al-Haj, M. Al-Hinai, M. Al-Abri, S. Rafiq, Valorization of waste Date pits biomass for biodiesel production in presence of green carbon catalyst, Energy Conversion and Management 135 (2017) 236-243.

673

674

675

676

677

678

679

680

681

682

[17] E. Lotero, Y. Liu, D.E. Lopez, K. Suwannakarn, D.A. Bruce, J.G. Goodwin, Synthesis of biodiesel via acid catalysis, Industrial \& engineering chemistry research 44(14) (2005) 5353-5363.

[18] S. Steinigeweg, J. Gmehling, Esterification of a fatty acid by reactive distillation, Industrial \& Engineering Chemistry Research 42(15) (2003) 3612-3619.

[19] G.G. Kombe, Chemical modification of high free fatty acid oils for biodiesel production, Fatty Acids, Elsevier2017, pp. 305-327.

[20] S. Shanmugam, B. Viswanathan, T. Varadarajan, Esterification by solid acid catalysts - a comparison, Journal of Molecular Catalysis A: Chemical 223(1-2) (2004) 143-147.

[21] A.I. Osman, N.C. Skillen, P.K.J. Robertson, D.W. Rooney, K. Morgan, Exploring the photocatalytic hydrogen production potential of titania doped with alumina derived from foil waste, International Journal of Hydrogen Energy (2020). 
[22] M. Cîrcu, A. Nan, G. Borodi, J. Liebscher, R. Turcu, Refinement of magnetite nanoparticles by coating with organic stabilizers, Nanomaterials 6(12) (2016) 228.

[23] M.I.A. Abdel Maksoud, A.M. Elgarahy, C. Farrell, A.a.H. Al-Muhtaseb, D.W. Rooney, A.I. Osman, Insight on water remediation application using magnetic nanomaterials and biosorbents, Coordination Chemistry Reviews 403 (2020) Article number 213096, (1-33).

[24] M. Mahmoudi, H. Hofmann, B. Rothen-Rutishauser, A. Petri-Fink, Assessing the in vitro and in vivo toxicity of superparamagnetic iron oxide nanoparticles, Chemical reviews 112(4) (2011) 2323-2338.

[25] A.H. Lu, E.e.L. Salabas, F. Schüth, Magnetic nanoparticles: synthesis, protection, functionalization, and application, Angewandte Chemie International Edition 46(8) (2007) 1222-1244.

[26] M. Calero, L. Gutiérrez, G. Salas, Y. Luengo, A. Lázaro, P. Acedo, M.P. Morales, R. Miranda, A. Villanueva, Efficient and safe internalization of magnetic iron oxide nanoparticles: two fundamental requirements for biomedical applications, Nanomedicine: Nanotechnology, Biology and Medicine 10(4) (2014) 733-743.

[27] M. Kazemi, A. Dadkhah, Antioxidant activity of date seed oils of fifteen varieties from iran, Orient J Chem 28(3) (2012) 1201-5.

[28] ISO. ISO 14044 Environmental Management. Life Cycle Assessment. Requirements and Guidelines. Int. Organ. Stand. 1, 1-46., (2006).

[29] I.A. Nehdi, H.M. Sbihi, S. Mokbli, U. Rashid, S.I. Al-Resayes, Yucca aloifolia oil methyl esters, Industrial Crops and Products 69 (2015) 257-262.

[30] A. Karmakar, S. Karmakar, S. Mukherjee, Properties of various plants and animals feedstocks for biodiesel production, Bioresource technology 101(19) (2010) 7201-7210.

[31] G. Knothe, R.O. Dunn, M.O. Bagby, Biodiesel: the use of vegetable oils and their derivatives as alternative diesel fuels, ACS symposium series, Washington, DC: American Chemical Society,[1974]-, 1997, pp. 172-208.

[32] U. Rashid, H.A. Rehman, I. Hussain, M. Ibrahim, M.S. Haider, Muskmelon (Cucumis melo) seed oil: A potential non-food oil source for biodiesel production, Energy 36(9) (2011) 5632-5639.

[33] U. Rashid, F. Anwar, M. Ashraf, M. Saleem, S. Yusup, Application of response surface methodology for optimizing transesterification of Moringa oleifera oil: Biodiesel production, Energy Conversion and Management 52(8-9) (2011) 3034-3042.

[34] R. Dutta, U. Sarkar, A. Mukherjee, Extraction of oil from Crotalaria Juncea seeds in a modified Soxhlet apparatus: physical and chemical characterization of a prospective bio-fuel, Fuel 116 (2014) 794802.

[35] M. Farooq, A. Ramli, D. Subbarao, Biodiesel production from waste cooking oil using bifunctional heterogeneous solid catalysts, Journal of Cleaner Production 59 (2013) 131-140.

[36] W. Wu, Z. Wu, T. Yu, C. Jiang, W.-S. Kim, Recent progress on magnetic iron oxide nanoparticles: synthesis, surface functional strategies and biomedical applications, Science and technology of advanced materials 16(2) (2015) 023501.

[37] G. Demazeau, Solvothermal reactions: an original route for the synthesis of novel materials, Journal of Materials Science 43(7) (2008) 2104-2114.

[38] Q. Lan, C. Liu, F. Yang, S. Liu, J. Xu, D. Sun, Synthesis of bilayer oleic acid-coated Fe3O4 nanoparticles and their application in $\mathrm{pH}$-responsive Pickering emulsions, Journal of colloid and interface science 310(1) (2007) 260-269.

[39] S. Pereira da Silva, D. Costa de Moraes, D. Samios, Iron Oxide Nanoparticles Coated with Polymer Derived from Epoxidized Oleic Acid and Cis-1, 2-Cyclohexanedicarboxylic Anhydride: Synthesis and Characterization, J Material Sci Eng 5(247) (2016) 2169-0022.1000247.

[40] M. Bloemen, W. Brullot, T.T. Luong, N. Geukens, A. Gils, T. Verbiest, Improved functionalization of oleic acid-coated iron oxide nanoparticles for biomedical applications, Journal of Nanoparticle Research 14(9) (2012) 1100. 
[41] M. Chai, Q. Tu, M. Lu, Y.J. Yang, Esterification pretreatment of free fatty acid in biodiesel production, from laboratory to industry, Fuel processing technology 125 (2014) 106-113.

[42] W. Visser, J.-M. Hoc, Expert software design strategies, Psychology of programming, Elsevier1990, pp. 235-249.

[43] A. Hooda, A. Nanda, M. Jain, V. Kumar, P. Rathee, Optimization and evaluation of gastroretentive ranitidine $\mathrm{HCl}$ microspheres by using design expert software, International journal of biological macromolecules 51(5) (2012) 691-700.

[44] ISO, ISO 14040: Environmental Management-Life Cycle Assessment-Principles and Framework; Technical Committee ISO/TC 207; ISO: Geneva, Switzerland. Int. Organ. Stand. 3, 1-20., (2006).

[45] A. Fridrihsone, F. Romagnoli, U. Cabulis, Environmental Life Cycle Assessment of Rapeseed and Rapeseed Oil Produced in Northern Europe: A Latvian Case Study, Sustainability 12(14) (2020) 5699.

[46] S. Photaworn, C. Tongurai, S. Kungsanunt, Process development of two-step esterification plus catalyst solution recycling on waste vegetable oil possessing high free fatty acid, Chemical Engineering and Processing: Process Intensification 118 (2017) 1-8.

[47] W. Marimón-Bolívar, E.E. González, Green synthesis with enhanced magnetization and life cycle assessment of Fe304 nanoparticles, Environmental Nanotechnology, Monitoring \& Management 9 (2018) 58-66.

[48] J. Dufour, D. Iribarren, Life cycle assessment of biodiesel production from free fatty acid-rich wastes, Renewable Energy 38(1) (2012) 155-162.

[49] G. Barjoveanu, O.-A. Pătrăuțanu, C. Teodosiu, I. Volf, Life cycle assessment of polyphenols extraction processes from waste biomass, Scientific Reports 10(1) (2020) 13632.

[50] Energy for oven drying. Available at: Grinder. Grinder properties. Available at: https://www.alibaba.com/product-detail/small-dry-date-seed-powdergrinder 60783543495.html?spm=a2700.7724857.0.0.547848825gOcaQ.

[51] Energy for oilseeds cooking machine. Available at: https://oil-mill-plant.com/oilseedspreprocessing-machines/oilseed-cooker.html.

[52] Energy for flaker roll. Available at: https://www.alibaba.com/product-detail/Automatic-Flaker-RollSoybean-Sunflower-

Peanut 60825427350.html?spm=a2700.pc countrysearch.main07.3.65122ef7wnDRym.

[53] Z.L. Chung, Y.H. Tan, Y.S. Chan, J. Kansedo, N.M. Mubarak, M. Ghasemi, M.O. Abdullah, Life cycle assessment of waste cooking oil for biodiesel production using waste chicken eggshell derived $\mathrm{CaO}$ as catalyst via transesterification, Biocatalysis and Agricultural Biotechnology 21 (2019) 101317.

[54] S. Pleanjai, S.H. Gheewala, Full chain energy analysis of biodiesel production from palm oil in Thailand, Applied Energy 86 (2009) S209-S214. 